\title{
Revisiting Proto-Kuki-Chin initials
}

\author{
Muhammad ZAKARIA | ORCID: 0000-0002-9480-6341 \\ Faculty of Languages and Cultures, Department of East Asian Languages \\ and Cultures, SOAS University of London, London, UK \\ rehman.zakaria@gmail.com
}

\begin{abstract}
There has been some progress in the reconstruction of Proto-Kuki-Chin (PKC), but, due to the previous lack of data from languages reflecting all the Kuki-Chin sub-groups, the available reconstructions merit fresh consideration. On the basis of new data of KukiChin (KC) languages, this paper proposes revisions to some of the reconstructions put forward by VanBik (2009). This paper particularly discusses PKC numerals in detail, especially the reconstruction of the numerals with prefixes.
\end{abstract}

\section{Keywords}

Proto Kuki-Chin - Southern Chin - phonology - numerals

\section{Résumé}

Malgré les progrès récents dans la reconstruction de Proto-Kuki-Chin (PKC), les reconstructions disponibles méritent d'être examinées à nouveau à la lumière de nouvelles données sur des langues Kuki-Chin (KC) jusqu' ici non-décrites. Cet article propose des révisions à certaines des reconstructions proposées par VanBik (20o9), en particulier des concernant les numéraux du PKC et leurs préfixes.

\section{Mots-clés}

Prot Kuki-Chin - Southern Chin - phonologie - numéraux 
This paper presents revisions to several reconstructions of Proto-Kuki-Chin (PKC) proposed by Van Bik (2009) and proposes reconstructions of PKC numerals based on recently available data of Kuki-Chin (KC) daughter languages. KC is a branch of the Tibeto-Burman language family. There are approximately 54 KC languages divided among Central, Northwestern, and Peripheral languages (Peterson 2017). This number of KC languages is an estimate, since many languages are yet to be documented. In addition, many varieties are yet to be determined either to have the status of a distinct language or a dialect. In particular, insecurity prevails regarding the Southern Chin (both Southwestern and Southeastern) varieties, a word list of which has been recently made available by the Language and Social Development Organization (LSDO) in Myanmar. Geographically, KC languages are widely spread among three countries: Bangladesh, India, and Myanmar.

Van Bik (2009: 1) estimates that there are more than a million Kuki-Chin speakers. A number of scholars have proposed genetic classifications of KC languages, among them Konow (1904), Shafer (1955), Bradley (1997), and Peterson (2000, 2017). Van Bik (2009) was the first to rigorously establish the existence of the KC subgroup, characterizing it with two innovations: the PKC *th- and verb-stem alternations. However, Peterson's (2000, 2017) is the most recent and the best-argued on both phonological and morphosyntactic grounds. Peterson (2017: 196) discusses the fate of the inherited ${ }^{*} \mathrm{r}$ in Kuki-Chin as a piece of phonological evidence in support of his Central/Peripheral subgrouping. In terms of morphosyntactic evidence, Peterson (2017: 202-203) repeats his discussion from Peterson (2000), which notes Northeastern and Southeastern languages' conservative nature by virtue of exhibiting reconstructible postverbal participant marking, prevalent use of the causative marker -sak in the same languages, a shared innovation of extending the use of the question marker $=m(V)$ from polar to content questions among the Peripheral languages, and use of the equational copula - $h i$ in Southeastern (Hyow) and Northeastern languages. It appears that further morphosyntactic evidence provided in Peterson (2017: 204) show differences between Southwestern (Khomic) and Southeastern Chin languages. Peterson (2017: 204) reports that as opposed to nominative-accusative alignment in Southwestern languages, Southeastern languages exhibit an ergative-absolutive system. There is limited participant marking in Southwestern languages, while participant marking is fairly developed in Southeastern languages. Peterson (2017: 204) also argues that even though Khumi does not show extensive use of stem alternations, as is typically found in Southeastern languages, the presence of stem alternations in 
FIGURE 1 Peterson's Centre-Peripheral classification of KC languages

Kuki-Chin

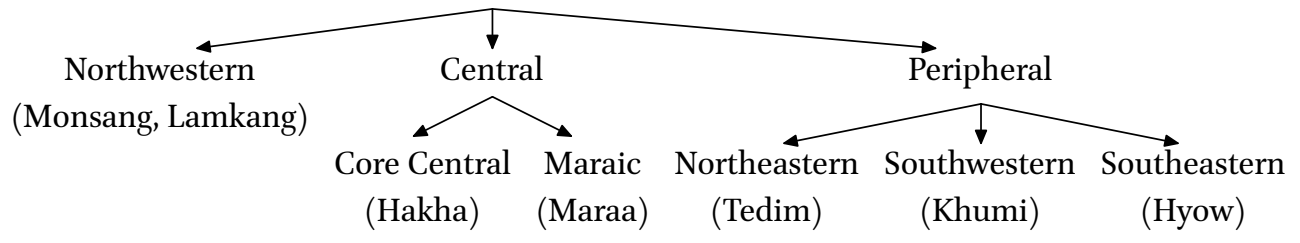

Rengmitca tells us that they must have been present at the Proto-Southwestern (Khomic) level. More recent study proposes the diachronic relation of Southwestern causative-applicative -hay and Southeastern middle -ey suffix (Peterson and Zakaria 2020). Peterson's (2017: 195) Central-Periphery model classifies the KC languages as Central (Core Central and Maraic), Northwestern, and Peripheral (Northeastern, Southeastern and Southwestern), as shown in Figure $1 .{ }^{1}$ Note that the position of Northwestern is still undetermined in the Central-Peripheral schema of Peterson (2017). The revisions and analysis presented in this paper support Peterson's Central-Periphery classification and elaborate his note on irregular reflexes of PKC ${ }^{*} \mathrm{r}$ - in Southeastern languages (see Section 3.3). However, more work is still required for sufficient evidence to fit Northwestern within the Central-Peripheral sub-grouping.

Much remains to be done in the reconstruction of PKC. A lack of data covering the range of daughter languages and limited work on Southern Chin (sc), in particular, has hobbled efforts so far. For example, Van Bik's 2009 reconstruction fails to consistently provide cognates in sc languages, for each of the reconstructions he proposes. This lack of consistent data from the languages of one of the significant subgroups makes Van Bik's (2009) reconstructions inconclusive. However, the new data in Southern Chin languages supports his claim that PKC *th- originates generally from an earlier sibilant (see Section 3.1).

The irregular correspondences of the root-initials in the cognates of тв languages is largely due to the prefixes/pre-initials involved in several phonological processes (see Bradley 2005, Matisoff 2017). Bradley (2005) notes how the root-finals of numerals are influenced by the following numeral classifiers (numerals and classifiers form compounds) and vice-versa. As opposed to Southwestern тв languages, numeral classifiers precede numerals in КС languages. The morpheme, $p z^{-}$, attached to numerals from 1 to 9 in Mizo, labelled as a prefix by Matisoff (2017: 16) is actually a classifier, as is evident

1 Peterson (2017) labels Khomic Southwestern and Southern as Southeastern. The names Southwestern and Southeastern appear in his subsequent revisions (Peterson 2018). I refer to both Southwestern and Southeastern as Southern Chin (sc) in this article. 
from the Hyow human classifier $p \hat{y} y$ and Lakher (Mara) pao (Savidge 19o8: 6). Savidge notes that $p a o$ becomes $p a$ as a numeral classifier for human in Lakher (Mara). In addition to the bound numeral classifiers, KC numerals can also bear prefixes/pre-initials, as in pun.m.hli 'four' (pun is a generic classifier in Asho, Hyow, and Laitu and $m$ - is a prefix) in Ann Asho. In order to reconstruct the numerals, one must then consider the CLS-PRF-R sequence in KC languages. ${ }^{2}$ In addition to numerals, the discussion of prefixes is also vital for addressing the attested diversity of root-initials in KC languages. For example, Van Bik (2009: 196) reconstructs PKC *haa- for 'tooth,' with a note that the cognate in Written Burmese is swa. The cognate for PKC *haa 'tooth' in Wakung has a voiceless fricative $f$-. Looking further into the cognates in other varieties listed in LSDO, Changpyang $n w a$, Kaang $f a$, and Areong Pa.fa can also be included in this grouping. Note that in all three languages PKC * $\mathrm{W}$-is reflected as $v$ - The cognate for 'tooth' in Changpyang shows that the voiceless root-initial in Wakung and Kaang originated in ${ }^{*}$ wa, with the sound change $v$ - $>f$-, which is caused by a voiceless prefix. The presence of a voiceless prefix is attested in Paletwa Uppu k.ho ( $\mathrm{PKC}{ }^{*} \mathrm{w}->$ Uppu $h$-). In addition, the root-initial in Changpyang has not undergone any change due to the prefix $n$. Therefore, underlying phonological process and lateral diffusions play an important and integral part in addressing the irregular sound changes in KC daughter languages. To further our understanding, I present the reconstructions of PKC numerals, giving due consideration to classifiers and prefixes in this paper. ${ }^{3}$

The primary methodology used in this paper is the exceptionlessness sound laws of the Neogrammarians (see Hale 2007, 2014). In accordance with an overall commitment to exceptionlessness, the sound changes in the KC languages have been addressed. When there are irregular correspondences among the cognates in daughter languages, the causes for language-specific sound changes have been established. In most of the cases, reconstructing prefixes have been able resolve any irregular correspondences in sc languages. In doing so, two more theoretical concepts have been applied: Hetzron's (1976: 92) principle of archaic heterogeneity, and contamination. I discuss these two theoretical concepts in detail in Section 4.

This paper is organized by giving a brief discussion on PKC syllables to clarify the phonotactics of PKC in Section 2. I provide my remarks and propose revision for some reconstructions of Van Bik (2009) in Section 3. In Section 4, I

2 'CLS' classifier, 'PRF' prefix and ' $\mathrm{R}$ ' root.

3 Note that even though the prefix/pre-initial does not provide any meaning synchronically, I prefer the term prefix to pre-initial since I deal with diachronic explanations. 
reconstruct numerals with prefixes. Finally, I give an overview of PKC phonology as reconstructed by different scholars in Section 5 , along with a summary of my own observations and suggestions.

The data for the revised reconstructions primarily comes from two sources: Van Bik (2009) and the LSDo wordlist. Van Bik (2009) bases his reconstructions of 1355 etyma on 12 KC languages-Hakha, Falam, Mizo, Zahau, Thado, Zo, Tedim, Sizang, Paite, Mindat Cho, Daai, Asho, Khumi, and Mara. The Lsdo wordlist of SC and a few Central Chin (CC) languages (both Core Central and Maraic), consist of 462 words, and is a result of LSD O's continuous language survey for developing orthography and literacy programs in indigenous languages of Myanmar. Note that the LSDO wordlist includes over $128 \mathrm{KC} \mathrm{(SC} \mathrm{and} \mathrm{CC)} \mathrm{vari-}$ eties. Among these 128 varieties, some clearly belong to the same language.

\section{$2 \quad$ The PKC syllables}

Both Khoi (2001: 102) and Van Bik (2009) propose PKC as having a syllable structure with a simple consonant or a consonant cluster for the onset, a simple consonant for the coda, and a bimoraic nucleus. Khoi's (2001:102) proposed canonical PKC syllable structure consists of an optional onset cluster of two consonants, $\mathrm{C}_{1} \mathrm{C}_{2}$. In contrast, Van Bik's (2009: 57) canonical PKC syllable structure may consist of an onset cluster formed with a consonantal prefix and an initial consonant or with an initial consonant and a glide. A and B respectively represent Khoi (2001:102) and Van Bik's (2009:57) canonical PKC syllable structures. The fundamental difference between the PKC canonical syllable structure by Khoi (2001) and Van Bik (2009) is that Khoi (2001:102) does not include any slot for prefix/pre-initial, which is presented by a Cp preceding the root in Van Bik's (2009) PKC canonical syllable structure. The addition of the prefixal slot in the PKC canonical syllable structure is certainly required in order to address the diversity of root-initials of same cognate in SC languages (see Section 3 and Section 4).
A. Khoi (2001)
$\left(\mathrm{C}_{1}\right)\left(\mathrm{C}_{2}\right) \mathrm{V}_{1}\left(\mathrm{~V}_{2}\right)\left(\mathrm{C}_{3}\right) \mathrm{T}^{4}$
B. $\operatorname{VanBik}(2009)$
$(\mathrm{Cp}) \mathrm{C}_{\mathrm{i}}(\mathrm{G}) \mathrm{V}(\mathrm{V})\left(\mathrm{C}_{\mathrm{f}}\right)$, where $\mathrm{Cp}=$ Prefix; $\mathrm{Ci}=$ Initial
Consonant; $\mathrm{G}=$ Glide; $\mathrm{Cf}=$ Final Consonant

4 Tone. 
Although both authors consider the PKC coda to consist of a single consonant, it is noteworthy that SC and Central Chin (CC) languages witness codas with a cluster of sonorants and the glottal stop, e.g. - $?$ l in Hyow or - $l$ ? in Hakha., as a result of verb-stem alternations. Though Van Bik (2009:10) sees verb-stem alternations as an innovative feature of KC languages, which evidently arose due to suffixation, he considers the coda itself as consisting of a single segment. It is possible to analyze the glottal stop in the coda position as either a phonetic component of a single coda consonant or as one element of a coda cluster. Hyman and Van Bik (2002) consider the combination of the sonorant and the glottal stop or vice versa as a unitary segment. Nonetheless, these authors do not provide minimal pairs that contrast simple and glottalized sonorants. In addition, the appearance of the glottal stop after sonorants cannot be treated as just a "phonetic impression" (Peterson, 2003: 410), since it is one of the indices of an important grammatical operation. The glottal stop, along with $-p,-t$, and $-k$, serves as the marker of Stem II verbs, e.g. Hyow, sho 'look' (Stem I) as opposed to shot 'look' (Stem II) and hngil 'forget' (Stem I) as opposed to hngi?l 'forget' (Stem II), in which the glottal stop marks the Stem II variant. Thus, the comparison between Stem I and Stem II verbs reveal that the glottal stop is as grammatical as other stops, $-p,-t$ and $-k$. These stops in Stem II are widely understood to be remnants of a historical nominalizer (Changte 1993, Matisoff 2003, King 2009) and clearly demonstrate a process of historical suffixation. Since the diachronic explanation requires treatment of the glottal stop as a separate segment, it would be simplest to apply the same analysis synchronically, all things being equal.

Additional synchronic evidence for not considering the sonorant clusters unitary segments comes from Hyow and Laitu phonotactics. Resyllabification is a salient phonological feature of these two sc languages, spoken in Bangladesh and Myanmar, respectively. In both languages, a CVC-VC morphemic sequence is resyllabified to CV-CVC, thus kîm 'descend' when affixed with the departative suffix -âl becomes kǵ-mâl 'climb down again'. An analogous process also applies to a morphemic sequence of CVCC-VC, where the coda of the first morpheme consists of a cluster of a glottal stop and a sonorant. Thus, CVCC-VC becomes CVC-CVC; for example, kórl 'pick up' when affixed with the -âl suffix kò?-lâl 'pick up again'. If the cluster were unitary, one would expect †kò-?lâl or the like, which is not found. Thus, when we consider whether $-? l,-? r,-? m$, etc. are best analyzed as unitary coda segments or coda clusters, the preponderance of evidence-both diachronic and synchronicpoints to coda clusters as the superior analysis. 
Van Bik (2009) posits his reconstructions of PKC on data from four Central Chin (Core Central and Maraic), four Southern Chin, and four Northeastern Chin (aka Northern Chin) languages. The following sub-sections look into some of Van Bik's (2009) proposals, which I think require some modification.

\subsection{PKC *th-}

According to Van Bik (2009), an inherited ${ }^{*} \mathrm{~s}$ - or ${ }^{*} 6$ - becomes *th-in PKC, except before the high-front vowel $i$ - in Northeastern Chin languages where the sibilant is retained, as in Tedim $s i^{1}$ 'blood', Paite si 'blood' and some other Southern Chin languages, as in M.Cho si 'blood'. The new data in Southern Chin languages also supports his claim (see Table 1). However, Mrusa, which is classified as a variety of Southern Khumi in the LSD o dataset, retains the sibilant in relevant cognates in Table 1 . The root-initial voiceless aspirated stop in the cognate for 'tree' in Mrusa may be due to a p- prefix/pre-initial. I have also included the Mrusa non-cognates (in round brackets) to show how lexically diverse it is from other KC languages. I could only trace OBur. mlāh (Hill, 2019: 277) for Mrusa mra.su 'arrow'. The retention of the sibilant and non-cognates for onethird of the words in Table 1 suggest that Mrusa is not a KC language and there are many loanwords in this language which are yet to be investigated.

\subsection{The reconstruction of *'s [/]- and *s $\boldsymbol{h}_{-}$}

Van Bik (2009) proposes to amend Ohno's (1965) reconstruction of *s [J]- to ${ }^{*} \mathrm{~s}^{\mathrm{h}}$-. Thus, as the ancestor of $s$ - in Mizo and most other languages, but hl- in M'Cho, Van Bik proposes PKC * $\mathrm{s}^{\mathrm{h}}$-. As Hill (2014:14) mentions, Van Bik proposes * $\mathrm{s}^{\mathrm{h}}$ - in place of Ohno's *ś- [S]- in reference to Hartmann's claim that in Daai the relevant segment is a voiceless aspirated alveolar fricative $\left[s^{h}\right]$-. This scenario is possible, but begs the question of the origin of PKC *s-. Moreover, the contrast between $s$ - and $s^{h}$ - is diachronically unstable (Jacques 2011). To reiterate, Van Bik (2009: 179) reconstructs PKC *s-, when M'Cho, Daai, and Hakha Lai reflects s- and he (2009: 186) reconstructs PKC $s^{h}$ - when M'Cho, Daai, and Hakha Lai reflect $h l_{-}, s^{h_{-}}$, and $s^{-}$, respectively. My own investigation of this matter shows problems in both directions. First, there are cases where his PKC *s- is reflected as $h l$ - in M'Cho and $s^{h}$-in Daai (Table 2).

On the other hand, the number of reconstructions Van Bik's (2009) cases of PKC * ${ }^{\mathrm{h}_{-}}>\mathrm{M}$ 'Cho hl- and PKC ${ }^{*} \mathrm{~s}^{\mathrm{h}_{-}}>$Daai $s^{h_{-}}$are very sparse. Out of those scant examples, two of his proposed reconstructions do not show the expected reflexes; the relevant exceptions are 'cold' and 'head hair' in M'Cho, and 'high' in Daai, as presented in Table 3. 
TABLE 1 Reflexes of PKC *th- in sc languages

\begin{tabular}{|c|c|c|c|c|c|c|c|}
\hline \multirow[t]{3}{*}{ PKC } & \multicolumn{6}{|c|}{ Peripheral } & \multirow[t]{3}{*}{ Gloss } \\
\hline & & & SE & & & sw & \\
\hline & Uppu & Changpyang & Ekai & Kaang & Hyow & Mrusa & \\
\hline *thii & $t^{h} i$ & $s^{h} i$ & a. $t^{h} i$ & $\int i$ & thî & (?a.wi?) & 'blood' \\
\hline *thiir & $t^{h} i$ & $s^{h} i$ & $t^{h} i$ & $\int i$ & thi & $s \varepsilon \eta$ & 'iron' \\
\hline *thin & $t^{h} i \eta$ & fin & $t^{h} i \eta$ & fin & thing & ?a.p $p^{h} a \eta$ & 'tree' \\
\hline *thay & ?. $t^{h} a i$ & ?a $t^{h} a i ?$ & $t^{h} i \eta . t^{h} a i$ & ?athe? & théry & Pa.sen & 'fruit' \\
\hline *thiin & $t^{h} i \eta$ & $s^{h}$ ij.ke? & $t^{h} i \eta$ & $\int: y$ & thing & (kว.e?) & 'ginger' \\
\hline$*$ thin & $t^{h}$ in & Pas hin & a. $t^{h_{\varepsilon} \eta}$ & fin & ithín & (Pa.plauy) & 'liver' \\
\hline *thaaw & ?.thau & $? a t^{h} a u$ & a.t $t^{h} a u$ & ?at $t^{h} a u$ & óthów & Pa.shau? & 'fat' \\
\hline *thi? & $t^{h}$ i.jin & $s^{h}$ i.jap & $t^{h} a . d u n . t \int a y$ & $\int i$ & thí? & (hu.se) & 'comb' \\
\hline *thal & $t^{h} y$ & $t^{h} a l$ & li. $t^{h} o . k a \eta$ & & thóltâm & (mra.su) & 'arrow' \\
\hline *thaw-I, tho?-II & Pi.k $k^{h} a . t^{h}$ & $t^{h}$ o.lo Pin & i.du.na.t $t_{\partial}$ & $t^{h}$ ou.lo kit & thów & Pit.s $s^{h}$. $h \varepsilon$ & 'get up' \\
\hline *thak-I, -tha?-II & $t^{h} a u$ & $t^{\text {hak Pin }}$ & $t^{h} a u . a u$ & $t^{h} a k k i$ & thókêy & (tz.rak.mi) & 'itchy' \\
\hline *thum & $p \cdot t^{h} u \eta$ & pa.t $t^{h} u m$ & pə.t $t^{h} u \eta$ & pa.th um & thûm & $s^{h} u m . j a ?$ & 'three' \\
\hline *thuuk & ?ay.th $u$ & & a.th $u$ & & úthúk & sig.he & ‘deep’ \\
\hline *thar & ?.tha & ?athai & a. $t^{h} a$ & ?athai & àthà & Pashar & 'new' \\
\hline *thu(u)r & $t^{h} u$ & $t^{h} u i$ ?in & a.t $t^{h} u$ & $t^{h} u i k i$ & úthú & $s^{h}$ Jr.diy & 'sour' \\
\hline *thak-I, tha?-II & $t^{\text {hip }}$ & fl:p Pin & a. $t^{h} e$ & $\int l i p k \dot{t}$ & thip & $s^{h} a$ & ‘spicy’ \\
\hline
\end{tabular}

TABLE 2 VanBik's PKC *s- in M'Cho and Daai ${ }^{\mathrm{a}}$

\begin{tabular}{|c|c|c|c|}
\hline PKC (KVB) & M'Cho & Daai & Gloss \\
\hline *suut & hlut & $s^{h} u u t$ & 'take off/undo/untie' \\
\hline *saa-I, saak-II & hlak & $s^{h} h a k$ & 'make/build' \\
\hline${ }^{*}$ suu-I, suuk-I I & hlawk & - & ‘wash' \\
\hline${ }^{*}$ sial & hlei & $s^{h} e$ & 'buffalo/mithun/cow' \\
\hline *suu-I, suk-II & hluk & $s^{h} u k$ & 'pound' \\
\hline *suan & - & $s^{h} \partial$ & 'plant' \\
\hline
\end{tabular}

a The cognates that do not show the expected reflexes of VanBik's *s- and ${ }^{*} \mathrm{~s}{ }^{\mathrm{h}}$ - are shaded. 
TABLE 3 Reflexes of VanBik's PKC * $\mathrm{s}^{\mathrm{h}}$ - in M'Cho and Daai

\begin{tabular}{llll}
\hline PкC (KVB) & M'Cho & Daai & Gloss \\
\hline${ }^{*} \mathbf{s}^{\mathbf{h}} \mathbf{a}$ & hlaa & $s^{h} a i$ & 'meat/flesh' \\
${ }^{*} \mathbf{s}^{\mathbf{h}} \mathbf{i k}$ & m'zuk & - & 'cold' \\
${ }^{*} \mathbf{s}^{\mathbf{h}} \mathbf{a m}$ & lu-mu & lu-s ${ }^{h}$ am & 'head hair' \\
${ }^{*} \mathbf{s}^{\mathbf{h}} \mathbf{a a n g}-\mathbf{I}, \mathbf{s}^{\mathbf{h}}$ aan-II & hlawng & hlüng & 'high' \\
${ }^{*} \mathbf{s}^{\mathbf{h}} \mathbf{u m}$ & hlum & $s^{h} u m$ & 'mortar' \\
${ }^{*} \mathbf{s}^{\mathbf{h}} \mathbf{a n} / \mathbf{s}^{\mathbf{h}} \mathbf{e n}$ & hlen & $s^{h} e n$ & 'red' \\
${ }^{*} \mathbf{s}^{\mathbf{h}} \mathbf{u u r} / \mathbf{s}^{\mathbf{h}}$ oor & hlui & - & 'squeeze' \\
& & & \\
\hline
\end{tabular}

TABLE 4 Reflexes of VanBik's PKC *s- in KC languages

\begin{tabular}{|c|c|c|c|c|c|c|c|c|}
\hline \multirow{2}{*}{$\begin{array}{l}\text { PKC } \\
\text { (KVB) }\end{array}$} & \multirow{2}{*}{$\begin{array}{l}\begin{array}{l}\text { Central } \\
\text { (Maraic) }\end{array} \\
\text { Taungtha }\end{array}$} & \multicolumn{6}{|c|}{ Peripheral } & \multirow[t]{2}{*}{ Gloss } \\
\hline & & Asho & Uppu & N. Laitu & E Ekai & Songlai & Hyow & \\
\hline $\begin{array}{l}\text { *saa-I, } \\
\text { *saat-II }\end{array}$ & $s^{h_{O}}$ & hlo? & Pto? & lin & a.hlo & alin & célông & 'hot' \\
\hline $\begin{array}{l}\text { *suu-I } \\
\text { *suk-II }\end{array}$ & $p^{h}{ }^{\prime} m$ & fu & son.ko.t $h^{h} u$ & $s^{h} O ?$ & soy.s ${ }^{h} u$ & say.s $s^{h} u k$ & fük & 'pound' \\
\hline *se? & & $z o / s o$ & ?.su & ?.so? & a.su & Pa sui? ?e & tsg̀? & 'bite' \\
\hline *sial & $s^{h} u m$ & $s^{h} \partial$ & $t \int^{h_{3}}$ & $t f^{h} a$ & $s^{h i \eta}$ & $s^{h} \varepsilon$ & fél & 'cow' \\
\hline *pa-sal & $(v a)$ & $\left(p^{h}\right.$ o.wa $)$ & (Pi.mo.po) & (?.pu.to) & po.ha & (pu.to) & (pótó) & 'husband' \\
\hline *suk & su. $k^{h} a \eta$ & kam. $t^{h} u \eta$ & $t \int^{h} i . k^{h} \cdot . t \partial y$ & nei.luy & $k^{h} u \eta . s^{h} u \eta . k^{h} \mathrm{~J}$ & $s^{h} u m(p) k^{h} \mathcal{E}$ & $\int u k \cdot k^{h} a$ & 'pestle' \\
\hline $\begin{array}{l}\text { *saa-I } \\
\text { *saak-II }\end{array}$ & te.lo & $t f^{h} a \eta \cdot t f^{h} a \eta \cdot f l$ & they.ra.hau & ?.Poi & e.fay.hau & ta.shak ki & & 'sing' \\
\hline${ }^{*}$ soop & tui. $s^{h} u$ & $t \int^{h} \partial$ & vat.ka.t $\int^{h} u$ & ?.s ${ }^{h} O$ & lu.a.sho & Pam.s $s^{h} \supset p$ & fóp & ‘wash' \\
\hline
\end{tabular}

The data in a number of sc languages, other than Daai and M.Cho, also suggests that the contrast between Van Bik's * $\mathrm{s}$ - and ${ }^{*} \mathrm{~s}^{\mathrm{h}}$ - is not very robust; his *sshows reflexes of both $h l$ - and $s^{h}$ - in SC languages. Van Bik reconstructs four words for 'hot' — *?uam/*?uap, *saa-I, and *saat-II, " $\operatorname{lin} /{ }^{*} l i n g$, and *lum/hlum. The Asho and Uppu cognates for 'hot' seem to compare with Van Bik's *saa-I and *sat-II. Other than Taungtha and Rungtu (Central) [?] $s^{h} O$, Mrusa (Khomic) $s^{h} a$.ding, Zotung (Central) $P a . s^{h}$, and Zophei (Maraic) $P a . s^{h} \mathcal{E}$ also reflect Van Bik's *s- $>s^{h}$ - for the word 'hot'. In fact, the cognates in Table 4 show that Van Bik's *s- > $s$ - is not consistent throughout the Sc languages. More interestingly, some of the cognate words reflect $t f$ - for Van Bik's *s-. 
TABLE 5 Reflexes of VanBik's * ${ }^{\mathrm{h}}$ - in KC languages

\begin{tabular}{|c|c|c|c|c|c|c|c|c|}
\hline PKC (KVB) & $\begin{array}{l}\text { Central } \\
\text { Maraic } \\
\text { Taungtha }\end{array}$ & \multicolumn{6}{|c|}{$\begin{array}{l}\text { Peripheral } \\
\text { SE }\end{array}$} & Gloss \\
\hline${ }^{*} \mathbf{s}^{\mathrm{h}} \mathbf{a}-\mathbf{k u} ?$ & $t^{h} \partial n$ & $k u$ & ku? & ku & $k u$ & ku? & hyún & 'porcupine' \\
\hline${ }^{*} \mathrm{~s}^{\mathrm{h}} \mathrm{am}$ & $s^{h} a m$ & $s^{h}$ ə.way & ?.t. $f^{h} a m$ & lu.sham & $s^{h} O \eta$ & lu.s ${ }^{h} a m$ & fam & 'hair' \\
\hline${ }^{*} \mathbf{s}^{\mathbf{h}} \mathbf{a a}$ & ?s ${ }^{h} a$ & $s^{h} O$ & P.t $\int^{h} O$ & P.shy & $a . s^{h} \partial \eta$ & $P a s^{h} \partial$ & sfo & 'meat' \\
\hline${ }^{*} \mathbf{s}^{\mathbf{h}} \mathbf{u m}$ & $s^{h}$ ung. $p^{h}$ s.mun & & $t \int^{h} u m$ & $s^{h}$ a. $p^{h_{\partial} . n e t . k^{h}}$ & $k^{h} u \eta \cdot s^{h} u \eta$ & $k \cdot s^{h} u m$ & fúk & 'mortar' \\
\hline${ }^{*} \mathbf{s}^{\mathrm{h}}$ ay & & fo & P.tf $f^{h} a u$ & ?.shau & a.?.shau & ?ak.sha: & $\int 3 w$ & 'long' \\
\hline $\begin{array}{l}{ }^{*} \mathrm{~s}^{\mathrm{h}} \text { aang-I, } \\
{ }^{*} \mathrm{~s}^{\mathrm{h}} \text { aan-II }\end{array}$ & & lun & tum & tun & ahlun & $\operatorname{tig} k i$ & & 'high' \\
\hline${ }^{*} \mathrm{~s}^{\mathbf{h}}$ an/shen & Pa.t $f^{h} i \eta$ & $\int \varepsilon \eta$ & fen & ?.s $s^{h}$ n & $a . s^{h} e \eta$ & ta.sh ${ }^{h} n$ & fén & 'red' \\
\hline${ }^{*} \mathbf{s}^{\mathrm{h}}$ uur/shoor & $s^{h} u p$ & & & & & Pas $s^{h} u i$ & & 'squeeze' \\
\hline
\end{tabular}

Likewise, Van Bik's reconstruction of PKC ${ }^{*} \mathrm{~s}^{\mathrm{h}}$ - is not consistent, as can be concluded from the examples presented in Table 5 . Notably, the reflexes of PKC ${ }^{*} \mathrm{~s}^{\mathrm{h}}$ - for the word 'high' are $\mathrm{hl}$ - in all the SC varieties listed. Moreover, in Hyow the word for 'porcupine' has a reflex of the voiceless palatal approximant for Van Bik's PKC * $\mathrm{s}^{\mathrm{h}}$ - and for the rest of the words it is reflected as $\int$-.

Hence, indexing the reflex of $h l$ - in M'Cho and taking account of the phonemic value of $s^{h}$ - only in Daai ${ }^{*} \mathrm{~s}^{\mathrm{h}}$ - are insufficient evidence for establishing a distinct proto-segment.

Furthermore, it appears that some of the Van Bik's reconstructions with *sand ${ }^{*} \mathrm{~s}^{\mathrm{h}}$ - initials have an affricate initial in the daughter languages, namely $t \mathrm{f}^{\mathrm{h}} u \mathrm{~m}$ 'mortar', $t \int^{\text {hy }}$ 'cow', $t f^{\text {ham }}$ 'hair', P.t th ${ }^{\text {au }}$ 'long', etc. in Kanpetlet Uppu. ${ }^{5}$ In this regard, Van Bik's claim that PKC *tsh-is only maintained in Mara and in some Central Chin languages, and simplified into a dental voiceless fricative is not true. Also, his claims that in Daai PKC *tsh- both merges with s- (2009:48) and is reflected as $s^{h_{-}}$(2009: 168) is an internal inconsistency in his analysis. Simply put, if there are cognates in KC daughter languages that reflect an affricate initial which can also be reconstructed at a higher level, as for the words 'hair', Burmese cham and Lashi tsham (Hill 2019: 57), and 'mortar', Burmese chum and Atsi tshum (Hill 2019: 57), then reconstructing *sh- at the PKC level is unwarranted.

The analysis presented so far in this section for revising Van Bik's PKC *sh- is summarized below.

5 Kanpetlet Uppu is a variety of the sc language Uppu. 
1. PKC *s- yields $h l$ - in M'Cho and $s^{h}$ - Daai.

2. Van Bik's proposal that PKC ${ }^{*} \mathrm{~s}^{\mathrm{h}_{-}}$yields $h l$ - in M'Cho and $s^{h_{-}}$in Daai is inconsistent.

3. Examples from sc languages show that $\mathrm{PKC}{ }^{*} \mathrm{~s}-\mathrm{can}$ also be reflected as $h l$ and $s^{h_{-}}$.

4. Van Bik's reconstructed words with ${ }^{*} \mathrm{~s}^{\mathrm{h}}$ - initial correspond to words with an affricate initial in sc languages and in languages outside KC.

\subsection{The reconstruction of * $\mathrm{r}$ -}

The treatment of PKC * $\mathrm{r}$ - in different languages is the centerpiece of evidence for Peterson's (2000, 2017) Centre-Periphery classification. PKC * ${ }^{*}$ - is retained in Central and Northwestern languages and has changed to either a velar fricative or a velar stop elsewhere (Peterson, 2017:196). However, Peterson (2017:196) posits that the change of Ртв * $\mathrm{r}$ - has occurred due to tendency towards pronunciation variations, which resulted in various reflexes of the Ртв * $r$ - in the Proto-Peripheral stage. Hill (2014) calls these changes 'Shafer's law'. Although Peterson (2017: 196) questions whether such a name is justified, since, apart from the transparent retention in Central Chin languages $\left({ }^{*} \mathrm{r}->\mathrm{r}\right.$, e.g. PKC *ril or *rul > Hakha ril 'intestine'), and the change in Tedim and M'Cho ( ${ }^{*} \mathrm{r}->\mathrm{g}$-, e.g. PKC *ril or *rul > Tedim gil'²ang ${ }^{2}$, K'Cho khi.gui 'intestine'), there are various treatments of initial * $\mathrm{r}$ - in $\mathrm{KC}$ languages, he nonetheless retains the term 'Shafer's law' for the change ${ }^{*} r->g$-. Hill's call for clarification of the split treatment of * $\mathrm{r}$ - in Sizang still remains unanswered. According to Peterson (2017: 198), the change * $\mathrm{r}->$ - $y$ - in Sizang, e.g. PKC *ril/*rul > Sizang ngïl 'entrails' is the regular change. The presence of the other non-nasal reflex, $l$ - of root-initial *r- in Sizang, e.g., luk 'six', salı 'seven', remains unknown. In sc languages, * $r$ - is reflected either as a palatal approximant or a velar fricative. The pre-root morpheme kho is lexicalized, found with nature-related words in Daai (Hartmann, 2009: 85) and also in Hyow (Zakaria 2017). Taking examples from Matupi, Daai, Kaang, Chinpon, and Hyow into account, Peterson (2017: 199-201) posits three treatments for PKC ${ }^{*} \mathrm{r}-$, namely $y$-, $\emptyset$ - and $\chi$ -

Fresh data on sc languages affords more insights into the reflexes of Van Bik's PKC * $r$ - in initial position. Looking at the cognate words for 'snake' in Table 6, one immediately finds that Khumi, Hyow, Southern Laitu, Northern Laitu, Ekai, and Khamaw have a bilabial initial. Noticing that this bilabial is also found in Tibetan sbrul < *smrul (Hill, 2019: 29), Tangkhul phórú (Mortensen, 2003: 5), Huishu Papharéy (Mortensen, 2003: 5), and Mikir phurul (Matisoff, 2003: 134), one must reconstruct the bilabial stop at the proto level for KC. I suggest reconstructing PKC *s-p-ruul 'snake'. The reconstruction of *s-p-ruul for 'snake' thus can account for Hyow phôl $<{ }^{*} \mathrm{p}^{\mathrm{h}}$ rgl $<{ }^{*} \mathrm{~s}-\mathrm{p}$-rul, Daar $p^{h j u}<{ }^{*} \mathrm{p}^{\mathrm{h}_{-} \mathrm{yu}}<{ }^{*} \mathrm{p}^{\mathrm{h}}-\mathrm{ru}<$ 
*s-p-rul, and Daai-Ngxang $k . k^{h} u<{ }^{*} \mathrm{p}^{\mathrm{h}} \mathrm{u}<{ }^{*} \mathrm{p}^{\mathrm{h}} \mathrm{ru}<{ }^{*}$ s-p-rul. ${ }^{6}$ Reconstructing the root-initial as *ph-, as suggested by one of the reviewers, would be problematic for addressing the root-initials in Central, e.g. rûul (Hakha) and Northeastern languages, e.g. gu: $l^{2}$ (Tedim), and indeed even for Daai $y u l$.

It is not only in the word 'snake' where there is good ground for revising Van Bik's * $r$-by adding prefixes. From the examples in Table 6, it is evident that other than the palatal approximant and the voiced velar fricative, Van Bik's PKC * $r$ is reflected as the post-alveolar fricative in the cognates of the numerals 'six', 'seven', and 'eight'. Reconstructing prefixes to the numeral roots let us explain these reflexes (see Section 4.6, Section 4.7 and Section 4.8).

It is evident from the cognate words of 'whistle' in Table 7 that the РКC form should be reconstructed *s-ruk. The *s- prefix has caused devoicing of the root-initial in Tedim. The Tedim comparison is a bit suspicious, at first glance, it seems to be a reduplicated onomatopoeic word. Subsequently, the root-initial $h$-in Thaipum, Northern Laitu and Khamaw indicates the change $\mathrm{h}-<{ }^{*} \mathrm{hr}-<{ }^{*} \mathrm{~s}-\mathrm{r}-$. Note that the root-initial voiceless aspirated velar stop points to a voiceless unaspirated velar stop prefix in Ekai. The root-initial has been dropped in the cognates of Khumi, Songlai-Hettui, and Daai.

Note that since Thaipum ru < PKC *s-ru?, where the devoicing of the rhotic is caused by the *s- prefix, I do not propose *hr- for the word 'bone'. Similarly, I propose P KC *s-ril in place of Van Bik's *ril or *rul 'intestine.? The affricate rootinitial in Southern Laitu, Northern Laitu, and Maitu points to the presence of a recent $t$-prefix. As noted by Matisoff (2017) the prefixes can through six types of phonological processes, this is an example of prefix fusion. The voiceless velar root-initial in Hyow and Ekai account for a k- prefix in those cognates, giving evidence for the change PKC *s-ril $>$ *hril $\rightarrow$ *k-hril $>$ *k-hil $>$ khcel in Hyow and PKC *s-ril $>$ *hril $\rightarrow{ }^{*} \mathrm{k}$-hril $>{ }^{*} \mathrm{k}$-hil $>$ khe in Ekai. It should also be noted that the affricate root-initial $t f^{h}$ - in Southern and Northern Laitu arise due to the $t$ prefix.

6 The root-initial changes to a velar stop through the process of assimilation of place with the $k$ - prefix in Daai-Ngxang. Also, *hr- is reflected as $h$ - in Daai-Ngxang (see LsDo list).

7 Van Bik (2009: 238) reconstructs the -ul rhyme in PKC *rul 'intestine' based on Khumi and M'Cho. This is problematic for addressing the root-initial in some other SC languages, e.g. Hyow khôl. 


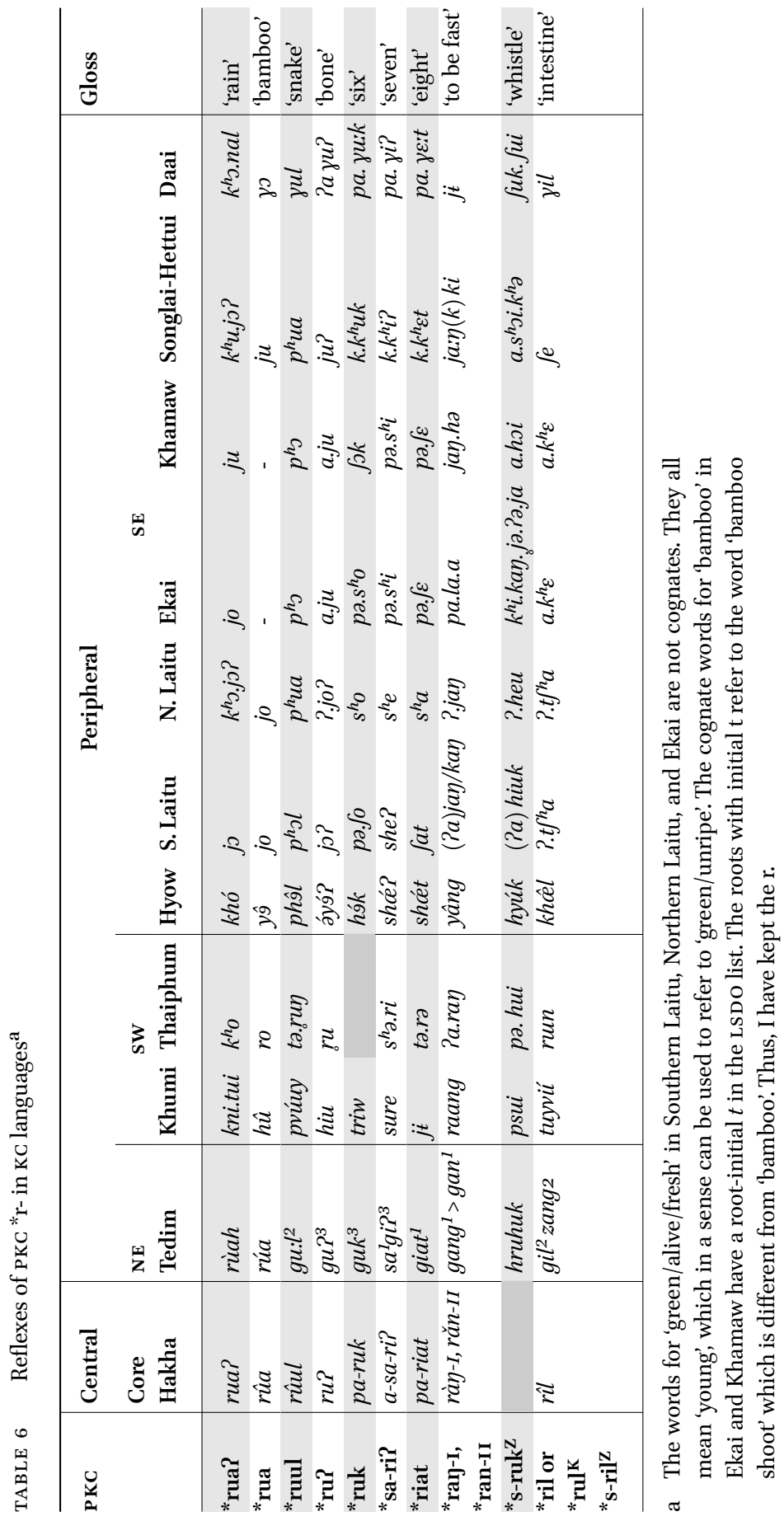


TABLE 7 Reflexes of PKC consonant cluster onset *hr- in daughter languages

\begin{tabular}{|c|c|c|c|c|c|c|c|c|c|c|c|}
\hline \multirow[t]{3}{*}{ PKC } & \multirow{3}{*}{$\begin{array}{l}\text { Central } \\
\text { Core } \\
\text { Hakha }\end{array}$} & \multicolumn{9}{|c|}{ Peripheral } & \multirow[t]{3}{*}{ Gloss } \\
\hline & & & si & & \multicolumn{6}{|c|}{ SE } & \\
\hline & & Tedim & Khumi & $\begin{array}{l}\text { Thai- } \\
\text { phum }\end{array}$ & Hyow & S. Laitu & N. Laitu & $\begin{array}{l}\text { Chang- } \\
\text { pyang }\end{array}$ & Khamaw & Daai & \\
\hline *hrik & hrik & $h i: k^{3}$ & hoey & Pa.ri & hék & $h \varepsilon k$ & $h \varepsilon k$ & xik & $\int a i$ & zik & 'louse' \\
\hline *hringK & $\begin{array}{l}\text { hrîy-I, } \\
\text { hrǐn-II }\end{array}$ & $\begin{array}{l}\text { hing }^{2}> \\
\text { hing }^{3}\end{array}$ & hóeyng & ka.rin & héng & & & Pa хiy & a.sin & 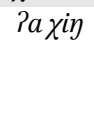 & $\begin{array}{l}\text { 'green/ } \\
\text { alive/ } \\
\text { fresh' }\end{array}$ \\
\hline${ }^{*}$ hrillz & & & t'ho & & hil & & hil & xil Pin & & & 'breathe' \\
\hline *hren' & & & taang & & hôn & hen & hen & $\chi^{\text {in }}$ & $s^{h} e n$ & & 'silver' \\
\hline${ }^{*} \mathrm{hraa}^{\mathrm{K}}$ & $|p a-h r a ̂ a|$ & & hóo & ra & há & ha & $h \tilde{a}$ & $p a \cdot \chi a$ & pa.hay & $p a \cdot \chi a$ & 'ten' \\
\hline${ }^{*}$ hrim $^{\text {Z }}$ & & & hueeng & & $\begin{array}{l}\text { á.phôe } \\
m\end{array}$ & 2. $p^{h} e m$ & $\begin{array}{l}(? a) \\
p^{h}{ }^{h: m}\end{array}$ & ?aхim & a.p $p^{h} \partial \eta$ & & 'old' \\
\hline
\end{tabular}

\subsection{The reconstruction of * $\mathrm{hr}$ -}

Originally, Van Bik (2009: 26o) proposed that PKC *hr- has the following reflexes: $h r$-(Mara), $h$-(NKC), $h r$-(CKC), gh-(M'Cho), $x$-(Daai), $h$-(Asho), and $h$ (Khumi). The fresh data of sc languages let us predict the prefixes/pre-initials that caused irregular correspondence of root-initials and propose new reconstructions which evidently had a *hr- initial.

In Table 7, I provide three examples along with Van Bik's own reconstructions showing the reflexes of PKC *hr- in the daughter languages, and propose reconstructions for 'breathe', 'silver', and 'old/ancient'.

Based on the reflexes of PKC *hr- in the languages illustrated in Table 7 , we can summarise the following generalization and conditions from 1 to 2 .

1. In general, $\mathrm{PKC}$ *hr- $>h$-in SC languages. The voiceless aspirate root-initial for 'old' is due to the $p$ - prefix.

2. $\quad$ PKC *hr- $>$ Changpyang and Daai (Kal-im variety) $\chi$, and in Khamaw $s-/ s^{h_{-}}$ before front vowels and $\int$ - when the original stop final is lost.

\subsection{The reconstruction of * $y$ -}

According to Ohno (1965), PKC *y- is retained in Khumi and according to Van Bik (2009) in M'Cho, Daai, and Asho as well as in Khumi. According to both scholars, PKC *y- elsewhere appears as $z$-. Hill (2014: 14) points out that in

8 Southern Laitu (?a) nəu, Northern Laitu ?.neu and Ekai a.nu are listed for 'alive' in the LSDo list. In fact, these are cognates among themselves of the word 'young', which can be used connotatively to refer to green/young referents. 
TABLE 8 Reflexes of PKC * $\mathrm{y}$ - in KC languages ${ }^{\mathrm{a}}$

\begin{tabular}{|c|c|c|c|c|c|c|c|c|c|c|c|c|}
\hline \multirow{4}{*}{$\begin{array}{l}\text { PKC } \\
(\mathrm{KVB})\end{array}$} & \multirow{4}{*}{$\begin{array}{l}\text { Central } \\
\text { Core } \\
\text { Hakha }\end{array}$} & \multicolumn{10}{|c|}{ Peripheral } & \multirow[t]{4}{*}{ Gloss } \\
\hline & & \multirow{3}{*}{ Tedim } & \multicolumn{4}{|c|}{ NE } & \multirow{3}{*}{$\begin{array}{l}\text { sw } \\
\text { Khumi }\end{array}$} & \multirow{3}{*}{ Hyow } & \multicolumn{2}{|c|}{ SE } & \multirow{3}{*}{ Daai } & \\
\hline & & & \multicolumn{2}{|c|}{ Sizang } & \multicolumn{2}{|c|}{ Thado } & & & Ekai & Khamaw & & \\
\hline & & & RD & KVB & HS & KVB & & & & & & \\
\hline *yaan & zăan & $\begin{array}{l}z a: n^{3} \\
\text { kim }^{3}\end{array}$ & yân & $z \bar{a} n$ & zàan & $\begin{array}{l}\text { yān, } \\
\text { aying }\end{array}$ & ving & '́xŷn & $\begin{array}{l}\text { a.jay. } \\
\text { sij }\end{array}$ & 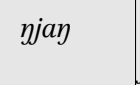 & $\begin{array}{l}k^{h} . \\
j i n\end{array}$ & 'night' \\
\hline *yuu & $z \hat{u} u$ & $z u^{2}$ & $y u ́, z u ́$ & zúu & zúu & $y \bar{u}$ & a.hmu & $y \hat{u}$ & ji.tui & ji.hoy & ju & 'rice beer' \\
\hline *yoon & $z \hat{o} o \eta$ & $z o: n g^{2}$ & $\begin{array}{l}\text { zong- } \\
\text { pui }\end{array}$ & zawng & zóoy & & zôoy & yóng & joy & joy & 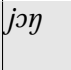 & 'monkey' \\
\hline *yuar & $\begin{array}{l}\text { zûar-I, } \\
\text { zǔar-II }\end{array}$ & $z u a k^{2}$ & yuak & $\begin{array}{l}\text { zuak } \\
\text { hı }\end{array}$ & $\begin{array}{l}\text { zúo?-I, } \\
\text { zùo-II }\end{array}$ & $y \bar{u} y \bar{o}$ & jó & $\begin{array}{l}\text { yò.I, } \\
\text { yó?.II }\end{array}$ & $a . j i$ & ji.a & $j a i$ & 'sell' \\
\hline
\end{tabular}

a The status of $a$ - and $?$ - in the cognate words those have it in Table 8 is a prefix. The Daai word for 'night' has a lexicalized old form $k h$, which is often found with words for natural phenomena (Hartmann, 2oog: $5^{8)}$.

principle the overwhelming number of languages showing z- calls for reconstructing ${ }^{*} \mathrm{z}$ - rather than ${ }^{*} \mathrm{y}$-. However, as he agrees, the examples at hand show the retention of $y$-in most of the Peripheral languages, the attested change of ${ }^{*} \mathrm{y}->z$ - in Thado and Sizang, and cognates outside of KC all validate PKC * $\mathrm{y}$ (Hakha zǔum-I/zǔum-II, wB yum 'believe' and Hakha zaap-I/za?-II, wв yap 'fan'). ${ }^{9}$ I present some examples in Table 8 showing the reflexes of PKC * $\mathrm{y}$ - in daughter languages. The cognates from different authors and time-period in Sizang (Rundall 1891) and Thado (Hodson 1905) attest the * $\mathrm{y}->z$ - change in Northeastern Kuki-Chin.

\subsection{The reconstruction of * $h y-[j-]$}

Although there are voiceless members of the nasals and the lateral among the reconstructed single onsets of both Ohno (1965) and Van Bik (2009), neither of them includes the voiceless approximant as a reconstructed segment, an absence also noted in Hill (2014: 24). In contrast, Peterson (2000: 94) reconstructed *hy-, for one morpheme, namely the question suffix that appears as

9 Shafer (1940:329) gives two comparisons external to РKC, namely Mizo $z u$ 'rice wine' to Chi. 西 $y u w X$ 'wine' (originally millet beer) and Mizo -zu 'rat' to Chi. 鼠 $y u w H$ 'weasel', but these comparisons are not valid because the relevant Chinese phonetic series (GSRiog6 and GSR1O79) point to laterals in Old Chinese. However, these two words might be loanwords from Middle Chinese into PKC (as proposed by Button 2011: vol i, pp. 8 o and 83). 
TABLE 9 Proposed reconstructed words with PKC *hy- root-initial

\begin{tabular}{|c|c|c|c|c|c|c|c|c|c|c|c|}
\hline \multirow{2}{*}{$\begin{array}{l}\text { PKC } \\
\text { KVB }\end{array}$} & \multirow{2}{*}{$\begin{array}{l}\text { Revised } \\
\text { PKC }\end{array}$} & \multirow{2}{*}{$\begin{array}{l}\text { Central } \\
\text { Core } \\
\text { Hakha }\end{array}$} & \multicolumn{8}{|c|}{ Peripheral } & \multirow[t]{2}{*}{ Gloss } \\
\hline & & & $\begin{array}{l}\text { NE } \\
\text { Tedim }\end{array}$ & $\begin{array}{l}\text { Sw } \\
\text { Khumi }\end{array}$ & Hyow & $\begin{array}{l}\text { S. } \\
\text { Laitu }\end{array}$ & $\begin{array}{l}\text { N. } \\
\text { Laitu }\end{array}$ & $\begin{array}{l}\text { SE } \\
\text { Ekai }\end{array}$ & Khamaw & Daai & \\
\hline *yuu & *pa-hyu & $z u ̀ u$ & $z u^{l} s a^{1}$ & рjии & hyû & hyu & phu & $p^{h} a . j u$ & $p a . s^{h} u$ & $f u$ & $\begin{array}{l}\text { 'mouse/ } \\
\text { rat' }\end{array}$ \\
\hline *yiing & *hyung & & $\begin{array}{l}k h u a^{2} \\
z i: n g^{2}\end{array}$ & ving & hyuy & $\begin{array}{l}\text { (?a) } \\
\text { hiun }\end{array}$ & P.juy & a.hjuy & a.s ${ }^{h} u \eta . h \partial$ & hip & 'be dark' \\
\hline $\begin{array}{l}\text { "yaang-I } \\
\text { *yaan-II }\end{array}$ & *hyang & $\begin{array}{l}\text { zâang-I } \\
\text { zăan-II }\end{array}$ & \begin{tabular}{|l|} 
zâang-I, \\
zàan-II
\end{tabular} & jang & hyón & P.jay & hyong & a.hjog.ka & $s^{h} o \eta \cdot h a$ & jay & $\begin{array}{l}\text { 'light } \\
\text { (weight)' }\end{array}$ \\
\hline $\begin{array}{l}\text { *yuul or } \\
\text { *yuuy }\end{array}$ & *hyul & $\begin{array}{l}z \hat{u} u l-I \\
z u l ?-I I\end{array}$ & & hui & hyul & hyun & a-yung & & & & 'follow' \\
\hline *yun & $\begin{array}{l}{ }^{*} \mathrm{p}- \\
\text { hyun }\end{array}$ & $z u ̌ n$ & $z u n^{3}$ & pyung & hyûn & hiun.tui & ?.$p^{h} u \eta$ & hju.tui & $p^{h j u}$ & $\begin{array}{l}\text { jun. } \\
\text { tui }\end{array}$ & 'urine' \\
\hline
\end{tabular}

-hiam in Tedim and -ziam in Sizang. Peterson's reconstruction is further supported by Button's comparison of the word 'follow' in Mizo /zùul, zùlh/ and Hyow |hyûl|, and part of the autonyms, zo of 'Mizo' and hyo of 'Hyow', themselves (Hill, 2014: 27). I propose to reconstruct *hy- in a number of additional words, presented in Table 9. The reconstructed PKC words and cognates in Central Chin are taken from Van Bik (2009). The Khumi examples come from my Khumi friend, Le Lung, in Bangladesh (per litteras, 15 November 2019). Finally, the cognate words in the rest of the South-Peripheral come from the LSDO dataset.

These examples in Table 9 suggest that the reconstructions of these etyma provided by Van Bik (2009) should be amended to have initial *hy-. We may infer that PKC *hy- was retained in the South-Peripheral but changed to $y$-in Khomic and to $z$ - in Central. Since the outcomes of * $y$ - and *hy- in the Northeastern languages are both $z$, it is simpler to presume that this outcome was reached in the ordered changes *hy- $>{ }^{*} \mathrm{y}_{-}>z$, , rather than supposing that * $\mathrm{y}_{-}>$ $z$-and *hy- $>z$-are independent changes. Remembering that Khomic languages also underwent the first of those changes, namely *hy- $>y$-, one can speculate that this change, since it is shared by both the Northeastern and Khomic languages, is an isogloss potentially linking these two groups. This *hy- $>y$-isogloss lends further support for Peterson's peripheral hypothesis.

The two sound changes *hy- $>y$ - and *hy- $>z$ - (probably via $y$-) do not fully account for the attested data. If we consider Khumi, we see that there are five reflexes of Van Bik's PKC *y-, namely $y$-, $v$-, $p$ - and $t s$-. Van Bik's PKC *y- $>y$ - works 
in Khumi for the word jang 'light (weight)'. However, other cognate words suggest that the root-initial for the word 'light (weight)' should be reconstructed to PKC *hy-, as in *hyang. Comparing the cognate words for 'mouse' and 'urine' where Khumi has an initial $p$-, it becomes clear that the initial $p$ - is a prefix. Furthermore, the Khamaw data shows that for the words 'mouse' and 'urine' two prefixes should be reconstructed, namely *pa- and "p-respectively. Hence, I suggest that the reconstructed word should also reflect the prefix in the PKC *pa-hyu 'mouse' and PKC *p-hyun 'urine'. The initial $\nu$-in ving 'be dark' reflects the *hy- $>v$ - before a high vowel, analogous to the change * $y->v$ - that also took place in Khumi (Peterson, 2017: 201).

In Khamaw, *hy- is reflected as the voiceless aspirated fricative $s^{\mathrm{h}}$ - in the words $p a . s^{\mathrm{h}} u$ 'mouse', a.s ${ }^{\mathrm{h}} u \eta$. ha 'be dark', and $s^{\mathrm{h}}$ oy.h . 'light (weight)'. It is not uncommon for languages to have a voiceless aspirated fricative originating in voiceless or aspirated sonorants. Jacques gives two cases in support of this development, namely in Cone Tibetan and Mazatec, ${ }^{*} \mathrm{r}>\mathcal{S}^{\mathrm{h}_{-}}$and ${ }^{*} \mathrm{j}->\int^{\mathrm{h}_{-}}$ (Chiquihuitlán Mazatec) respectively (Jacques, 2011: 1524). Thus, PKC *hy- > Khamaw $s^{\mathrm{h}_{-}}$in the given cognate roots in Table 9 is an explainable change. In short, the initial of the roots of the words presented in Table 9 should be reconstructed as *hy- in place of Van Bik's *y-.

\section{$4 \quad$ Reconstructions of PKC numerals}

Sc languages are conservative in terms of the initials and innovative in their rhymes, whereas Northeastern Chin languages are the opposite; they are innovative in their initials, but conservative in terms of their rhymes. This polarized feature of archaism and innovation on the opposite sides of a syllable nucleus in Southern and Northeastern Chin languages is not reflected in the works published so far. Van Bik (2009) and Button (2011) do fine jobs with their reconstructions of rhymes, but they were unable to avail themselves of sufficient SC data to reconstruct the prefixes. Since the LSDO wordlist is available, it is now high time to look at the prefixes more systematically and address the irregular correspondences of root-initials of numerals. In this section, I propose reconstructions of prefixes attached to numerals.

Numerals in KC languages are of particular interest because of sporadic and diverse prefixes attached to them. In order to decide which of the several attested prefixes, $p$-, $t$-, $k$-, $m$-, and $n g$-, in the numerals presented in Table 10 reflect inheritance and which innovations, I follow two methods. First, I consult Hetzron's (1976) paper on the principles of genetic reconstructions. According to Hetzron's (1976: 92) principle of archaic heterogeneity, if there are three 
languages $\mathrm{A}, \mathrm{B}$, and $\mathrm{C}$ with homogeneous grammatical feature $\mathrm{x}$ - in language $A$, homogenous feature $y$ - in language $B$, and heterogeneity, sometimes $x$ - and sometimes $y$ - in language $C$, then it is more likely that language $C$ is closest to the archaic system. Based on this principle of Hetzron (1976), we can see that Thaiphum cognates show the greatest heterogeneity in terms of the prefixes attached to the numerals one to eight in Table 10. Secondly, I use the possibility of contamination as a guide to reconstructing the prefixes of numerals in KC languages. If two adjacent numerals have the same initial, then it is possible that one has been copied to the other via contamination. For example, Russian девять < Proto-Slavic *devętь 'nine', has a d- initial instead of a n- initial (pIE ${ }^{*} h_{1}$ néwñ, Greek $\dot{\varepsilon} v v \varepsilon \varepsilon \alpha$, Latin novem, English nine) under the influence of the initial seen in де́сять < *desętь 'ten', in which the d-is inherited (PIE *dékm, Greek $\delta \dot{\varepsilon} x \alpha$, Latin decem). Another example of contamination spreading initials in IE numerals is Indo-European * $\mathrm{k}^{\mathrm{w}}$ etwốr 'four' irregularly becoming

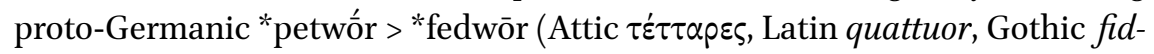
wōr, Old English féower) under the influence of the *p- in *pénk ${ }^{\mathrm{w}} \mathrm{e}$ 'five' (Greek $\pi \varepsilon \dot{v} \tau \varepsilon$, Sanskrit páñca, Lithuanian penki). Note that the initials of numerals only spread through contamination one at a time in consecutive numerals. Thus, we would never see the initial of 'seven' copied directly on to 'two' or 'one'. The evidence of Thaiphum and Songlai (Hettui) is crucial since these two languages provide data to show how the prefixes spread from one numeral to another by contamination. For example, the Thaiphum data show that either numeral two or three had the $k$ - prefix in the proto-language. On the other hand, we can infer from the Songlai data that either numeral three or numeral four had the $k$-prefix in the proto-language. Now, comparing the data of Thaiphum and Songlai, we can claim that numeral three had the $k$-prefix in the proto-language for sure. In Thaiphum, the $k$-prefix is potentially copied from numeral three to numeral two, while in Songlai, this may have happened from numeral three to numeral four.

In order to reconstruct the numerals, one needs to consider the use of numeral classifiers, which are commonly found in тв languages and the phonological process of assimilation of place and manner. The LSDO list includes numeral classifiers along with the numerals in citation forms for several sC languages. The presence of numeral classifiers in citation forms of numerals demonstrates that the speakers of these languages conceptualize numerals in relation to the size, shape, or other distinct properties of referents. Therefore, the citation forms of numerals represent the actual conceptualization of numerals by speakers. For reconstructing the numerals with prefixes, there are two important features to be noted. First, the initials and finals of the commonly used numeral classifiers play a vital role in assimilation. The commonly 
used classifiers in KC languages have a $p$ - initial, e.g. pao (reduced to $p a-$ ) in Lakher (Maraic), páy (for human), and pûm (generic) in Hyow, pun 'Cls' Asho (Ann variety), p $x i$ in Laitu (Minbya variety), $p i n$ and $p a k$ in Daai (Amsoi variety), etc. The running $p a$-prefix in Mizo numerals from 1 to 10 is also evidently the same classifier for human. The finals of these commonly used classifiers include either a palatal approximant, a nasal or a stop final. Second, the phonological process of assimilation is very common in Sc languages. Due to assimilation, the root-initial of numerals do not show the expected reflexes. For example, $t^{\mathrm{h}}$ la:y pum mat (person CLS one) 'one person' in Daai (Paletwa variety) demonstrates a bilabial nasal root-initial instead of the expected alveolar nasal due to the assimilation of place with the preceding classifier. In another instance, $p a k . k^{\mathrm{h}} i \mathrm{r}^{\text {' }}$ 'wo' in Daai (Amsoi variety) demonstrates a velar root-initial instead of the expected alveolar nasal due to the assimilation of place. Furthermore, pun.no 'one' in Asho (Ann variety) demonstrates a voiced root-initial instead of the expected voiceless initial due to the assimilation of voice. The variation in the forms of numerals due to classifiers is also found in тв languages outside of the Kc languages (Bradley 2005).

The unexpected correspondences in the cognates of numerals are also found due to prefixes. After carefully investigating the prefixes attached to numerals, I have found out that some prefixes are inherited and some are innovative in KC languages. For example, the $p a$ - prefix in Changpyang, Mara, and Hakha originate in a numeral classifier for human, e.g. pao in Lakher (Savidge 1908: 6 ), whereas the $p \partial$ - prefix attached to numeral four and five in Thaiphum and Khumi are inherited. Note that based on Hetzron's (1976) principle of heterogeneity, we have already argued that Thaiphum numerals contain the prefixes which are likely to be inherited. The argument that the $p a$ - prefix in Changpyang, Mara, and Hakha are originally numeral classifiers is based on the examples found in numeral four in Mara, e.g. pэ.pə.li (Thantlang variety), рә.pə.li (Matu variety), and pao-pali (Lakher, Savidge 1908: 6). The preceding numerals in these varieties of Mara, Thantlang, and Matu include only the $p$ - prefix, while Lakher includes only the pao. Note that Savidge (1908: 6) notes that pao becomes $p a$ when a human referent is indicated. Therefore, it is plausible that the $p(V)$ - prefix is a reduced form of the numeral classifier for humans. This is expected since the speakers of these languages conceptualize numerals in reference to an object, generally to humans. On the other hand, a language like Thaiphum demonstrates the presence of a p- prefix only in the numerals which originally had it in the proto-language. When reconstructing the prefixes of numerals, one needs to consider the status of the bilabial prefix.

Based on these preliminary findings, I now reconstruct the numerals from one to ten in the following sub-sections. 


\subsection{The reconstruction of the numeral one}

Van Bik (2009: 145) reconstructs PKC *khat, *?at and *hat for numeral one, based mostly on his data for Central and Northeastern languages. VanBik's reconstructions have a $t$ final. On the other hand, external comparisons such as Tibetan gčig < * gtyek 'one' and Chinese 隻 tsyek < *tek 'one of a pair' (Hill, 2019: 223) show a velar final. If we look at the cognates for numeral one in Table 10, we see that most of the cognates have a $-t$ final, whereas Thaipum has a glottal stop final and Asho has an open syllable. ${ }^{10}$ Interestingly, Hyow has both the $-t$ and $-k$ final forms for numeral one. The bound word for numeral one in Hyow is - $a k$, which reflects the retention of the *-k final seen in Tibetan. The bound numeral -ak must be used with a numeral classifier, as in khrông pótsóngák 'one person'. The Hyow unbound numeral one is hngát. Based on the two different endings in the cognates of numeral one in $\mathrm{KC}$ languages, I propose to reconstruct two forms, "k-hngat and *t-ak, for numeral one in PKC.

Looking at Van Bik's reconstruction of numeral one, we see that his PKC *hat 'one' is based on Khumi ha (Van Bik, 20o9: 35). Many of the Sc languages have the form hat for numeral one, in which the vowel is nasalized. Van Bik's reconstruction does not give any account of the nasalization of the vowel in the cognates of numeral one. However, we can provide an explanation of the nasalized vowel looking at the cognates of numeral one in some sc languages. For example, the free numeral hngát in Hyow is also pronounced as hãt. Likewise, in Laitu, which is spoken in Myanmar and has a close affinity to Hyow, the initial velar nasal consonant of $h$ ngat 'one' becomes $h<{ }^{*} \mathrm{hng}$-, resulting in hngat $>$ hãt. A similar process also accounts for Daai-Ngxang $p a$ hãt and cognates of numeral one in many other sc languages (see Table 10 and the LSDo list). In Hyow, Laitu, and Daai-Ngxang, the vowel following the initial nasal consonant becomes nasalized in its presence and remains nasalized, after the initial is lost, reflecting the fact that the initial of the numeral was, in fact, a nasal stop. A plain vowel in place of the nasalized vowel is also found in some cognates of numeral one, as in Asho pə.ho, Mayinn p.hə.wat, Khumi ha, etc. (LSDO 2019). These examples of numeral one reflect a well-known cycle of sound change, according to which nasalized vowels are the results of assimilation with nasal consonants. Eventually, nasal vowels may become phonemic in languages after the loss of nasal consonants over a period. At the end of this cycle of sound change, the nasalized vowels become plain vowels. Therefore, we should reconstruct numeral one as PKC *hngat.

10 There is no PKC *k- > KC $t$ - or PKC *t- > KC $k$-, except for the word PKC *khaat > KC khaak 'bitter' (Van Bik, 2009: 424). 
In some sc languages, the root-initial of numeral one contains a bilabial nasal consonant. For example, the cognates of numeral one in Changpyang and Songlai-Hettui have a bilabial nasal root-initial. The root-initial of numeral one, mat, in Changpyang and Songlai-Hettui presents evidence for the phonological process of assimilation of place. The root-initial bilabial nasal in these two languages assimilated with the generic classifier pum, which warrants the sound changes *pum hngat > *pum hmat > pum mat. Over time, the root-initial in these languages have permanently changed to bilabial nasal stop, resulting in their presence in the citation forms without the classifier. Such account of assimilation is attested in Daai (Paletwa variety), e.g. $t^{\mathrm{h}}$ la:y pum mat 'one person'.

Van Bik (2009) reconstructs two more forms of numeral one in PKC, *?at and *khat. If we reconstruct *hngat for numeral one, it is not difficult to explain ?at, while the inverse does not work. On the other hand, the root-initial $k$ - in Hakha pa-khat and Mara pá-khā, Thado Kuki khàt Vanbik's PKC *khat is, in fact, a prefix, which can be broken down as *k-hat. Originally, the $k$ - prefix went through the following series of changes attested in Hakha, Mara, Thado Kuki and many other sc languages: *k-hngat > *k-hãt > *k-hat > khat.

The cognates of numeral one in bur.ta? in Thaiphum, ${ }^{11}$ p.bua in $\mathrm{Uppu}^{12}$ and l. do? in Wakung ${ }^{13}$ show the most irregular correspondences. This might be due to the amalgamation of prefixes and assimilation caused by numeral classifiers. We need access to further data on these languages to explain the irregularities conclusively.

In view of the analysis presented above, the root for numeral one should be reconstructed as PKC *hngat.

Now, to find out the PKC prefix for numeral one, let's take a look at the available data in Table 10. The cognates in Uppu p.bua and Mayinn p.ha.wat include a

11 Thaiphum word bu?.tว? for numeral one is a compound, where bu? might be a classifier. It seems to be cognate with the classifier pum in Hyow and Asho. The ta? presents the actual numeral in Thaiphum, in which the $t$ - reflects the Tibetan initial and looks like a prefix.

12 I do not have any explanation at hand currently for the Uppu word p.bua for numeral one. Though the bu? in Thaiphum numeral one bu?.tə? looks similar to the -bu- of Uppu numeral one $p$.bua. Since $p$-is a prefix, -bu-cannot be a classifier. However, considering the bound numeral one in Hyow, $-a k$, the $-a$ seems representing the root-initial for numeral one in Uppu.

13 The Wakung word lo.do? is particularly interesting because the roots of numeral two to nine come in between $b-d o$ ?, as in $l o-n i-d o$ ? 'two'. The $l o$ part might be numeral one itself and is repeated at the beginning of each numeral from 'two' to 'ten' denoting the indefinite article $a$, while the $d o$ ? might be an emphatic marker, also found in Hyow as an emphatic marker (=d9?), which speakers use to encode assertion to their answer. 
bilabial stop initial prefix, $p$-. The bilabial stop-initial morpheme, $p$, in Asho is regular and shows the variant, pon (cognate with the generic classifier pum), in numerals five to ten. Thus, the allomorphs, $p$ a and pan, are not prefixes in Asho, rather they are numeral classifiers. The morpheme $t u$ in Changpyanag might be a prefix originating in $t z-/ t$ - The presence of pa-prefix in Changpyang numeral two to ten suffices not to consider $t u$ - as a numeral classifier. However, the $p a-$ prefix in Changpyang itself originates in a numeral classifier, as is in Mara and Hakha.

Therefore, we mostly have two contenders for the prefixal position in numeral one, ${ }^{*} \mathrm{p}$ - and ${ }^{*} \mathrm{k}$-. The $k$ - prefix seems to be the older one, which can be confirmed from the absence of $k$ - as a true prefix in any of the daughter languages. The $p$ - prefix attached to numeral one in Uppu and Mayinn appears due to contamination. Therefore, I propose PKC *k-hngat for numeral one.

Finally, based on the $t$ - prefix attached to the root of Thaiphum numeral one, Tibetan gčig < *gtyek 'one' and this like, the second form for numeral one should be reconstructed as PKC *t-ak.

\subsection{The reconstruction of the numeral two}

For the numeral two, Van Bik (2009) reconstructs both *ni? and *hni?. Van Bik (2009: 207) shows that PKC *hn- is regularly reflected as $n$-in Northeastern and some sc languages, while it is retained in Mara and Central languages. Therefore, according to Van Bik's account of reflexes of PKC *hn- in the daughter languages, Mara should have a voiceless alveolar nasal initial for numeral two, but it has a voiced alveolar nasal, which is probably the reason behind's Van Bik's reconstruction of both PKC *ni? and *hni?.

The cognates in Table 10 show both the voiced and voiceless variants of the root-initial of numeral two. If we reconstruct PKC *hni?, then we can explain the voiceless velar nasal initial by providing the evidence that $h n$ and $h n g$ - merge as $h n g$ - in M'Cho, as well as in Songlai, e.g. PKC *hnaa > Songlai (Hettui) hng .ku 'ear', PKC *hniit > Songlai (Hettui) Pa.hngu? 'blow', PKC *hnaay > Songlai (Hettui) hnguai 'pus'. Reconstructing the voiceless alveolar nasal root-initial can also account for the voiced alveolar nasal root-initial in Wakung, Thado Kuki, Sizang and Khumi have a voiced alveolar nasal rootinitial, because PKC * $h n$ - is reflected as $n$ - in these languages. However, reconstructing the voiceless root-initial is problematic for Mara because PKC *hn- is retained in Mara, but the cognate of numeral two in Mara $p \bar{a}-n o$ has a voiced nasal root-initial. Hence, I propose to construct PKC *ni? for numeral two. I explain the cognates of numeral two with voiceless root-initial through the reconstruction of a prefix. 
Now, if we look at the prefixes attached to the root of numeral two in cognates, we find several contenders for the prefix position. In Table 10, we see that Uppu, Changpyang, Mayinn, Mara, and Hakha bear a bilabial prefix. The absence of the $p a$ - prefix in numeral three in Van Bik's (2009) data is not known. Van Bik's (1987) clearly includes $p a$ - with numeral three. I have already mentioned that the $p a$ - prefix originates in a classifier in Changpyang, Mara, and Hakha, while the $p$ - in Uppu and Mayinn is originally a prefix. The pə- morpheme in Asho pa.hni originates in a generic numeral pum/pun. The LSDo data shows that the Daai varieties spoken in Matupi and Paletwa, and the Songlai varieties bear a velar nasal prefix attached to the root. Finally, Thaiphum shows a velar stop prefix attached to the root. Hence, we find two prefixes, $h$ ng-and $k$-, contending for the prefixal position in the proto root, but I reconstruct PKC *k-ni? with a $k$ - prefix for two reasons.

First, hng- can be explained by contamination and assimilation, as in Songlai $\eta . y j i ?<k . \eta y i ?<{ }^{*}$ yi? < *k.yi? < *k.ni?. In Songlai, the root-initial assimilated by place with the *k- prefix first and then the *k- prefix caused the devoicing of the root-initial. The second $k$-prefix is copied from numeral three in Songlai by contamination. Finally, the $k$ - prefix went through assimilation of manner with the root-initial. The cognates of numeral two in Uppu and Mayinn have a voiceless stop root-initial. The change *k-ni? > *hni? > hi must have occurred in Uppu hi or Mayinn $h i$ 'two', which is evident from other examples in these two languages, e.g. PKC *hnoot > *hoot > ?.ho? 'wipe', PKC *hnim > *hnun > *hum $\rightarrow p$-hun $\rightarrow p^{\mathrm{h}}$ un 'submerge', PKC *hnor or *hnur $>$ *hn $>{ }^{*} \mathrm{~h} \supset \rightarrow t-h \jmath \rightarrow t^{\mathrm{h}} \mathrm{\jmath}$ 'rub' in Uppu. Note that the $p$ - prefix in the cognates of Numeral two in Uppu and Mayinn appears due to contamination from numeral three. The devoicing of the root-initial of numeral two by the *k- prefix did not occur in Mara, Thado Kuki, Sizang, and Khumi.

Second, looking at KC external languages strengthens the proposal that * $\mathrm{k}$ should be reconstructed as the prefix attached to numeral two in the protolanguage. For example, the Tibetan word for numeral two is gñis. Therefore, based on the Tibetan word-initial velar stop and above-mentioned discussion, I propose that for numeral two we should reconstruct PKC *k-ni?.

\subsection{The reconstruction of the numeral three}

Van Bik reconstructs *thum without a prefix for numeral three. Based on the LSDo listed languages, I agree with Van Bik's reconstruction PKC *thum for the root of numeral three. Notably, Thaiphum, Asho, Uppu Wakung, Mayin, and Khumi have -ng final instead of the reconstructed *-m. Van Bik (2009: 349) shows that ${ }^{*}$-um is reflexed as -ung in Khumi. Therefore, -ung is an expected reflex of PKC *-um. 
The cognates listed in Table 10 indicates that there are two prefixes which can be reconstructed at the proto-level. There is a $p$ - prefix in Uppu $p . t^{h} u \eta$, and Mayinn $p . t^{h} u \eta$. The $p$ - prefix in Uppu and Mayinn numeral three is a contamination from numeral 4 (see Section 4.4). Thaiphum and Songlai in Table 10 bear a $k$ - prefix. Based on Thaiphum ka.hni 'two' and ka.thum 'three', we can infer that the $k$-prefix must have been attached to numeral two or three in the proto-language. Again, Songlai $k \cdot t^{\mathrm{h}} u m$ 'three' and $k \cdot p^{\mathrm{h}} i$ 'four' indicate that the $k$-prefix must have been attached to either numeral three or numeral four in the proto-language. A velar prefix is also attested outside the KC, as in Tibetan gsum (Hill 2019: 35). It is not an accident that the $k$ - prefix resembles the velar prefix in Tibetan gsum. Summing up these observations, we can say that, the $k$ prefix was originally attached to numeral three in PKC. In Songlai, the $k$-prefix has been copied to numeral four from numeral three. Finally, as a KC external example, we can refer to Tibetan. Therefore, all the evidence is compatible with the reconstruction PKC *k-thum 'three'.

\subsection{The reconstruction of the numeral four}

Van Bik reconstructs PKC *lii for numeral four. In Table 10, we see that Uppu and Mayinn have voiceless lateral fricative root-initial and Hyow has a voiceless lateral approximant initial. If we look at Van Bik's reflexes of PKC *hl- in the daughter languages, we see that Northeastern and peripheral languages show $l$ - in place of PKC *hl-, but Mara and Central languages retain PKC *hl- (Van Bik, 2009: 265). If we reconstruct the root-initial of numeral four with a voiceless lateral approximant, as in PKC *hlii, then it will fit Van Bik's reflexes of PKC *hl-in Northeastern languages, M'Cho and Khumi, but not in Mara and Central Chin languages, as demonstrated by Mara li and Hakha lii. On the other hand, if we reconstruct the numeral with a voiced lateral approximant root-initial, PKC *lii, then it requires an explanation of the voiceless root-initials found in Hyow hli, Asho $l i$ and Mayinn ${ }_{i}$. Based on these preliminary findings, I reconstruct PKC *lii 'four', with a voiced root-initial. I will justify my reconstruction through the discussion of prefixes in the following paragraph.

Considering the cognates listed in Table 10, we find four prefixes, $p(V)$ in Thaiphum, Uppu, Changpyang, Mara, Hakha, and Khumi, $m$ - in Asho and Wakung, $n g$ - in Mayinn, and $k$-Songlai, which can be reconstructed in the proto-language. Note that the $p \partial$ - morpheme in Asho is a classifier.

I have already mentioned that the pa- prefix in Changpyang, Mara, and Hakha originates in a classifier. The cognates of numeral four, po.pə.li, pə.pə.li and pao pa-li in Thantlang Mara, Matupi Mara, and Lakher respectively strengthen my analysis further. The cognates in these three varieties of Mara demonstrate that the $p a$ - prefix in Changpyang, Mara and Hakha is different 
than that of the immediate $p$ - prefix observed in Mara cognates, which must be inherited. The cognates in Uppu and Mayinn are also evident of that, since the contamination of the $p$ - prefix to previous three numerals, from one to three, is only possible from numeral four. The cognates of numeral four in Mara varieties also provide critical evidence to reconstructing the prefix, because it is possible to argue then that the devoicing of the root-initials in Uppu, Mayinn, Hyow, and languages the like must have happened due to the *p- prefix of PKC *p-lii. In Thaiphum and Khumi, the proto $p$-prefix did not cause the devoicing of the root-initial but rather it is retained. In Mara and Hakha, they must have been dropped. The $p$-prefix in Uppu pti 'four' simply devoiced the root-initial, but was not dropped.

We find the $m$ - prefix in Asho $m$.li and Wakung ma.li. The m- prefix is, in fact, observed in many of the LSDO languages. It seems to be the remnant of the generic numeral $p V N$. Thus, the $m$ - prefix attached to the root of numeral four in Asho must have taken place due to the nasal final of the generic classifier $p ə n$ (cognate with pum), which can be shown as *pon-p-hli > *pon-m-hli > pa.m.hli. The $m$ - prefix in Wakung is copied from numeral five.

The Songlai word for numeral four, $k . p^{\mathrm{h}} i$, includes the $k$ - prefix. First, PKC *hl$>$ Songlai $h$-is exemplified in other cognates too, as in PKC *hlaay > Songlai (Hettui) he? 'buy', PKC *hlun $>$ *hung $>$ *heng $\rightarrow{ }^{*}$ p-heng $>$ Songlai (Hettui) $p^{\text {h }}$ eng 'old', PKC *hliap > Songlai (Hettui) khu-hia 'shadow' etc. Hence, the $p$ - in k. $p^{\mathbf{h}_{i}}$ 'four' in Songlai (Hettui) is inherited. The $k$ - prefix is then copied from numeral three $k$-thum to numeral four $k \cdot p^{\mathrm{h}} i$ in Songlai (Hettui). The series of changes in Songlai (Hettui) numeral four can be presented as PKC *p-lii > *p-hli > *p-hi > $\mathrm{p}^{\mathrm{h}} \mathrm{i} \rightarrow k \cdot p^{\mathrm{h}}{ }^{\prime}$ 'four'.

Finally, the $n g$ - prefix in Mayinn $n g . t i$ is due to the final nasal of the generic numeral classifier $p V N$, which is evident from pig.ti 'four' in Minkya, a variety spoken near to Mayinn. ${ }^{14}$ However, the absence of any full form of the classifier with other numerals in Minkya casts doubt on the status of the morpheme. Whatever the status of the morpheme piy, it is safe to say that the $y$-prefix attached to numeral four in Mayinn originates in piy.

Based on the discussion above, inference from Thaipum that at least 'four' or 'five' had a $p$ - prefix attached to the root of numeral four in the proto-language and the KC-external evidence that the word for numeral four in Tibetan bzi i originates from Proto Tibetan *blyi following Benedict's law (Hill, 2019: 219), we can reconstruct the bilabial stop as the prefix attached to numeral four, PKC * $\mathrm{p}$-lii.

14 Both are classified as Southern Asho language by LSDO ans spoken in the same township, Seddutaya, in Rakhine state of Myanmar. 


\subsection{The reconstruction of the numeral five}

Van Bik (2009: 215) reconstructs *ngaa for numeral five. Since Tib. lina 'five', Bur. $\dot{n} a \bar{h}$, Chi. 五 $n g u X<{ }^{*}$ C.nfa? (Hill, 2019: 269) show a voiced velar nasal rootinitial, I agree with Van Bik's PKC *ng- as the root-initial for numeral five. The cognates of numeral five presented in Table 10 shows that Asho ந̊o, Mayinn ந̊ㄱ, Hyow hngó and Songlai (Hettui) ma have voiceless nasal root-initial. The voiceless nasal root-initial can be explained by the prefix attached to numeral five in the proto-language.

From the cognates listed in Table 10, we can separate five prefixes, $p$ - in Thaiphum, $p a$ - in Changpyang, Mara and Hakha, $m \partial$ - in Wakung, $p$ - in Khumi and $\eta$ - in Songlai (Hettui). It is important to note here that the pəy- in Asho pəy. is a generic classifier. On the other hand, the velar nasal prefix in Songlai (Hettui) $y . m a$ must have been copied from numeral four $k . p^{h}$. The prefix then went through assimilation of manner, resulting in $\eta$-.

I propose *p-nga as the reconstruction for numeral five, with a *p- prefix. Fellner and Hill (2019a: 107) contend that the $p a$ - prefix of numeral five in Hakha $p a-\eta \hat{a} a$ and Mizo pa-ngá are contaminated by the bilabial initial in numeral four, as in Mizo pà-lí, Tib. bźi < "blyi, Kuröp ble. Nonetheless, the status of the $p a$ - prefix in Mara, Hakha, Mizo and languages alike does not affect the reconstruction of any of the numerals because my analysis suggests that the $p a$-in both Hakha and Mizo along with Changpyang originates from a numeral classifier, as attested in Lakher pao > pa (Savidge 1908: 6). On the other hand, the $p$ - and $p$ - prefixes in Thaiphum and Khumi respectively are inherited and cognates. The p-prefix is also the strongest candidate of all to be reconstructed as the proto-prefix for numeral five, because by reconstructing * $\mathrm{p}$ - as the prefix, we can explain the voiceless root-initials in the cognates of numeral five. In Asho, Mayinn, and Hyow, the devoicing of the root-initial must have happened due to the *p- prefix, hng- < PKC *p-ng-. In Uppu and Songlai (Hettui), the bilabial nasal root-initial must have first gone through assimilation of place with the *p- prefix. Then, the *p- prefix has caused the devoicing of the root-initial. The series of sound changes in Uppu and Songlai (Hettui) numeral five can be presented as Uppu mo $<{ }^{*}$ p-mo $<$ "p-nga and Songlai (Hettui) ma $<{ }^{*}$-ma $<{ }^{*}$ pnga. In Wakung, the *p- prefix itself assimilated by place of manner with the root initial, as in ma.ya $<$ *m-ya $<$ *p-ya.

If we look outside of KC, we find Fellner and Hill (2019a: 107) suggesting that in Matisoff's (2003: 149) Ртв *l/b-nga 'five', the lateral is most likely correct, with the evidence of Tibetan lina and Dakpa $l e^{31} y e^{3}$ 'five'. However, Dempsey (1995: 209) suggests that the $r$-/l- prefix attached to numeral five in many тв languages, e.g. Tibetan lna, are of no great antiquity. Also, in his response to Fellner and Hill (2019), Handel (2019: 139) suggests it is likely that the lateral is 
an innovation specific of Tibetan and closely related languages. On the other hand, the bilabial prefix is found across the тв family, e.g. Naga $p(h) n g a$, Baric $b$-nga (Dempsey, 1995: 221). Hence, the presence of the $p$ - prefix in the overwhelming number of languages and the analysis presented above suggest that PKC had the *p- prefix attached to numeral five.

\subsection{The reconstruction of the numeral six}

For numeral six, Van Bik's reconstruction PKC *ruk has the expected reflexes in the Northeastern and the Central KC languages, but Khumi and the other SC languages show deviant reflexes (see Table 6 and Table 10) of the root-initial of numeral six. The cognates in the sc languages for the numerals 'six', 'seven' and 'eight' presented in Table 6 show that Van Bik's ${ }^{*} r$ - appears as $s-/ \int-/ s^{h_{-}}$, except in Songlai and Daai. The question remains to be answered here is why the SC languages show the $s-/ \int-/ s^{\mathrm{h}}$. The cognates of numeral six in Hyow, Southern Laitu and Khamaw have voiceless palato-alveolar fricative root-initial, while the cognate forms in Northern Laitu and Ekai have a voiceless unaspirated alveolar fricative. Since PKC * $\mathrm{r}$ - is otherwise reflexed as $y$ - in sc, it is plausible that the voiceless root-initial of cognates for the numeral 'six' has been caused by something, presumably by a prefix.

There are three possible prefixes which can be derived from the cognates listed in Table 10, $t$-, $k$ - and $p a$-. The presence of the $t$ - prefix with numeral six in Thaipum tz.ru?, Wakung ta.ru and Khumi triw strongly suggest that the PKC numeral six must have had the $t$ - prefix since in these three languages there is no opportunity of getting the $t$ - prefix by contamination. Furthermore, instead of the expected reflex of $v$ - of PKC ${ }^{*} \mathrm{r}$ - in Khumi, we see that the form retains the Proto ${ }^{*} \mathrm{r}$ - with an attached $t$ - prefix, which happens because the $t$ - prefix formed a cluster with the root-initial voiced rhotic. Looking at Tibetan drug, we may think that the a *d-prefix has changed to $t$ - in Khumi. However, Hill's (2019: 227) rebuttal of Nishida's conjecture regarding the correspondence of Tibetan $d r$ - to wв $k h r$ - puts such an explanation to question. Giving examples from the next of kin to Tibetan, Hill (2019: 227) shows that the Tibetan $d r$ - corresponds to the velar stop and rhotic cluster in three East Bodish languages: Bumthap, Dakpa, and Khengkha. To further strengthen Hill's explanation, one can take a look at Dempsey (1995), in which he elaborately discusses the numeral six. Dempsey (1995: 236) proposes the change $g r->d r$ . He explains that the change $g r->d r$ - is very much possible since it follows a natural pathway of assimilation, velar+apical $>$ apical+apical (note that Mizo underwent the same type of assimilation from PKC *kr- > tr-, Ohno's law). Hence, the Tibetan form for the numeral 'six' derives from *gruk, which went through dental assimilation before writing was introduced to Tibet (Dempsey, 
1995: 237). Dempsey furthermore shows examples corresponding to the velar stop and rhotic cluster of $d r$ - in Tibetan loanwords into Lepcha and Monpa (Dempsey, 1995: 237-238). Hence, the $t$ - prefix in Khumi $t$-riw 'six' is a development independent of the $d$ - seen in Tibetan drug 'six'. Nonetheless, note that other languages also show $t$-, as in Japhug ku-tgry < PGR * *ko-trok (Jacques, 2004: 294 \& 2017: 4). Now, this very $t$ - prefix has originally caused the devoicing of the root-initial of numeral six, which ultimately followed the series of sound changes *t-r- > ${ }^{*}$ hr- $>$ *hy $>s h-\left[\int\right]$ in Hyow, Southern Laitu and Khamaw. In Songlai, the velar stop must be the reflex of PKC *hr- $<$ *t-r- via velar fricative, which is evident from PKC *hrik > Songlai $\chi$ tak 'louse', PKC *hra $>$ Songlai $k^{\mathrm{h}} a$ 'termite'.

In Songlai, the numeral six $k \cdot k^{\mathrm{h}} u k$ must have had the $k$ - prefix by contamination from numeral seven $k . k^{\mathrm{h}} i$ ? . The pa- prefix in Changpyang, Mara and Hakha, as discussed earlier, is innovative. The cha- in Mara reflects the affrication of the *t- prefix, ${ }^{*}$ t-ruk $>$ *ta-ru $>$ cha-ru. ${ }^{15}$

Hence, based on the discussion on the prefix attached to numeral 'six' and looking at the KC cognate words for the numeral 'six', it seems reasonable to reconstruct * $t$ - as the prefix to the protoform. Accordingly, I suggest the reconstruction PKC *t-ruk for the numeral 'six'.

\subsection{The reconstruction of numeral seven}

Van Bik (2009: 184) reconstructs the PKC *sa-ri? for numeral seven. His reconstruction appears problematic in explaining reflexes in languages appearing in the LSDo list. If we reconstruct a voiced rhotic root-initial, it still continues to be problematic, because the PKC ${ }^{*} \mathrm{r}$ - is reflected as either $y$ - or $x$ - in Wakung, as in PKC *ru? > Wakung ?a.xu? 'bone', PKC *ray > Wakung jay 'be fast'. Furthermore, PKC *hr- is consistently reflected as $x$ - in Wakung, as in PKC *hrik $>$ Wakung xi? 'louse', PKC *hril > Wakung $x e . d \varepsilon$ 'choose', PKC *hraak > Songlai $x a . d \varepsilon$ 'shout', $\mathrm{PKC}$ *hril > Wakung ?a.tz.xi 'intestine'. Also, note that PKC *r- does not become Songlai $g$-, PKC *ru? > Songlai ju? 'bone'. Therefore, Van Bik's explanation of M'Cho $k^{\mathrm{h}_{-}}<{ }^{*}(\mathrm{~s}+\mathrm{g})-<{ }^{*}(\mathrm{~s}+\mathrm{r})-$ does not work in Songlai. Van Bik's explanation rather works for both M'Cho and Songlai. There are two possible ways to resolve this-either we reconstruct a voiceless rhotic as the root-initial or we reconstruct a prefix other than *s- and explain the irregular reflexes in the relevant languages.

$15 c h$-refers to [ts-] in Mara (VanBik 2009). 


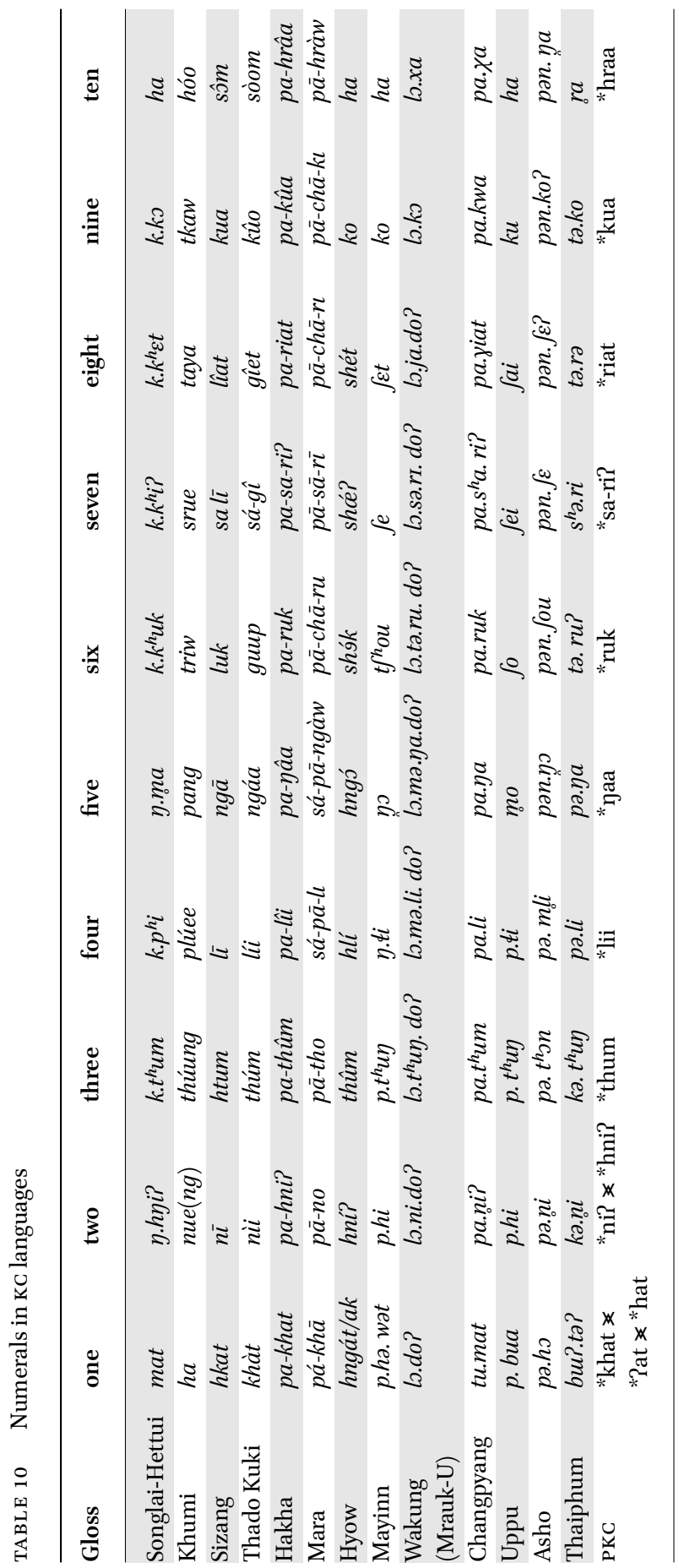


If we propose to reconstruct a voiceless rhotic as the root-initial of numeral seven, then there is no explanation for the root-initial in Mara, Hakha, Thado Kuki, Sizang, and Khumi, because the root-initials of numeral seven in these languages contain regular reflexes of PKC * $\mathrm{r}$-, namely $r$ - in Mara, $r$ - in Hakha, gin Thado Kuki and $l$ - in Sizang. However, reconstructing a voiceless root-initial can explain the root-initial of numeral seven in sc languages. The Thaiphum cognate $s^{\mathrm{h}}$ ari for numeral seven shows the aspiration of the voiceless fricative prefix by the h- of PKC *hr-. Hence, the change in Thaipum is *s-hri? $>{ }^{*} \mathrm{~s}^{\mathrm{h}}$-ri $>s^{\mathrm{h}}$-ri. ${ }^{16} \mathrm{~A}$ similar thing happens in Changpyang. In Hyow and languages the like, the *-r- is dropped, which is expected in these languages (see Table 7), as in PKC *s-hri? > *s-hæ? > shce? The aspiration caused by $-h$ - is preserved in some Asho varieties, e.g. $p \partial n . s^{\mathrm{h}} i$ (Thandwe variety), Minkya $s^{\mathrm{h}} i$, etc, but is lost in Hyow. In addition, the alveolar fricative merges with the post-alveolar fricative in Hyow. The Songlai cognate $k . k^{\mathrm{h}} i$ ? for numeral seven demonstrates the PKC *hr- > Songlai $x$-/ $/ k^{\mathrm{h}}$-, the change I have already discussed in Section 4.6 To strengthen our argument in reconstructing a voiceless root-initial for numeral seven, if we claim that the voicing of the root-initial *hr- in numeral seven is lost in Mara, Hakha and Khumi, then it does not fit the regular reflexes of PKC *hr- in these languages either, because PKC *hr- is retained in Mara and Hakha and changes to $h$-in Khumi.

To make further progress in reconstructing numeral seven, we need to establish that there was a prefix other than *s-. Note that the *s- prefix alone cannot account for the cognates of numeral seven in some sc languages in which we see a voiceless root-initial and an aspirated prefix, as in Ng'ga $k \cdot k^{h} \cdot x i i_{0}{ }^{17}$ Now, if we look at the cognate of numeral seven in Daai (Amsoi variety) $k^{h} y i$, we see that the $-y$-is a reflex of РКC ${ }^{*} \mathrm{r}$-. From here, we can infer that the $k$ - must be the prefix, which has been aspirated by the *s- prefix. Now, if we reconstruct *s-k-ri?, then we can explain the cognate of numeral seven in Daai as $k^{\mathrm{b}} y i$ ? < ${ }^{*} \mathrm{~s}-$ k-yi? < *s-k-ri?. In the KC languages which have a voiced rhotic root-initial, the root-initial of numeral seven did not go through the process of voicing assimilation by the $k$ - prefix, whereas the languages which have a fricative initial for numeral seven and in which * $\mathrm{r}$ - is lost account for the series of changes PKC *s$\mathrm{k}-\mathrm{r}(\mathrm{V})>{ }^{*} \mathrm{~s}-\mathrm{hr}(\mathrm{V})>{ }^{*} \mathrm{hy}(\mathrm{V})>s^{\mathrm{h}} / s / \int(V)$, as attested by Uppu fei, Mayinn $\int \mathrm{e}$ and Hyow shó? in Table 10. Also, in Songlai, $k-k^{h} i ?>{ }^{*} \mathrm{k}$-xi? $<{ }^{*} \mathrm{k}-\mathrm{hri}$ < ${ }^{*} \mathrm{~s}$-k-ri? and in Ng'ga, $k^{h} x \ddot{t i}<{ }^{*} \mathrm{k}^{\mathrm{h}}-\mathrm{xii}<{ }^{*} \mathrm{~s}-\mathrm{k}-\mathrm{xi} ?<{ }^{*} \mathrm{~s}-\mathrm{k}-\mathrm{hri}$ < ${ }^{*} \mathrm{~s}-\mathrm{k}-\mathrm{ri}$. Note that the aspiration

16 PKC *hr- is retained in Thaiphum. The proposed explanation demonstrates a re-attribution of the voicing feature.

17 The unaspirated $k$ - is innovative. 
of the *k-in Ng'ga obligatorily requires the *s- prefix to be reconstructed for the proto-numeral.

The pa- prefix is already established as being derived from a numeral classifier. Hence, reconstructing the *s- prefix along with *k-keeps with the analysis made in the preceding paragraph. Besides, $s$ - can be even traced back to many languages outside KC, as in Gyalrong kə6nés (Zhang, 2020: 274), Japhug kmєnuz (Jacques, 2017: 5), Tangsa s.ñət (Dempsey, 1995: 277), Naga s-nat (Dempsey, 1995: 277). ${ }^{18}$ Thus, I reconstruct numeral seven as PKC *s-k-ri?.

\subsection{The reconstruction of numeral eight}

Van Bik (2009: 235) reconstructs the PKC *riat for numeral eight. Again, his reconstruction seems to be erroneous at first glance, e.g. PKC * $r$ - > Songlai $g$ is not possible; thus, PKC * riat $>$ Songlai $k^{\mathrm{h}}$ et cannot be explained. However, if we consider his reconstruction along with a voiceless stop prefix attached to it, then we can explain the voiceless root-initials of numeral eight in Asho, Mayinn, Hyow and Songlai-Hettui. The cognates of numeral eight in Changpyang and Wakung are interesting in this regard. If we compare the cognates of numeral eight with the cognates of numeral seven in these two languages, $s^{h} a . r i$ and sa.r respectively, we notice that the root-initial $r$ - does not have the regular correspondences in numeral seven, but they have regular correspondences of * $r$ - in numeral eight, $\gamma$ - and $j$ - in Changpyang and Wakung respectively. Comparing cognates of other words in these two languages, I have noticed that whenever the root-initial has either the $t$ - or $k$ - prefix then the ${ }^{*} r$ - does not change in these two languages, as happens in numeral seven. In contrast, if there is no prefix, then there are regular correspondences of ${ }^{*} \mathrm{r}$ - in Changpyang and Wakung, as in PKC *ru? > Changpyang $\gamma u$ ?, Wakung ju? 'bone'. A detail discussion on the regular reflexes of PKC *r- and irregular reflexes of PKC * $r$ - due to the presence of prefixes would require a separate article.

Based on the cognates listed in Table 10, there are two prefixes which can be attested in the sc languages for numeral eight, $k$ - and $t$-. Note that the $p a-$ prefix, as discussed earlier, originates in a numeral classifier in Changpyang, Mara and Hakha. The $k$ - prefix attached to numeral eight in Songlai-Hettui has been copied from numeral seven through contamination. The $t$ - prefix attached to numeral eight and nine in Thaiphum and Khumi points to the obligatory presence of the $t$ - prefix either in numeral eight or numeral nine in the protolanguage. On KC internal grounds, it is not clear whether *t- should be reconstructed as the prefix only in eight (but not nine), only in nine (but not eight), or

18 Outside KC, the root-initial of numeral seven contains a nasal consonant. 
both in eight and nine. The comparative data for nine (see Section 4.9) suggests that ${ }^{*} t$ - is inherited in nine and has probably spread analogically to eight. Thus, on the basis of Tibetan brgyad < *bryat 'eight', Chinese 八 peat $<{ }^{*} \mathrm{p}^{\mathrm{S}}$ ret, I propose $\mathrm{PKC}$ *p-riat for numeral eight. This solution may seem to have a somewhat arbitrary character, but we know that there must be a prefix in the numeral because the prefix is responsible for devoicing the root-initial. Since there is no KC internal evidence to tell us what the prefix was, we might as well use the external evidence. Therefore, the $p$ - prefix is responsible for the devoicing of the root-initial first. The voiceless rhotic then changes to voiceless fricative, as seen for numeral six in Section 4.6. In Hyow, the series of changes can be represented as *p-riat $>$ *hriat $>$ *hyat $>$ shcet 'eight'. Thus, based on the analysis made above, I propose to reconstruct PKC *p-riat for numeral eight. Note that the -cha- prefix in numeral eight in Mara has been copied from numeral nine. This particular prefix is also found with many other words in Mara, e.g. cha-kha 'ascend/steep', cha-lei 'buy' (see Savidge 1908: 45-51).

\subsection{The reconstruction of the numeral nine}

Van Bik reconstructs PKC *kua for numeral nine. Similar to other numerals, Van Bik's reconstructions for numeral nine does not include any prefix. His reconstruction of the numeral root *kua appears to work for the languages listed in LSDO.

For the prefixal position, we have two contenders $k$ - and $t$-. Since Thaipum and Khumi have the $t$ - prefix in both numeral eight and nine and based on the evidence provided we have already reconstructed *p- for numeral eight, numeral nine must have had *t-in the proto-language. The $k$-in Songlai-Hettui is copied from eight to nine through contamination. Thus, I propose PKC *t-kua for numeral nine. Note that the *t- prefix also corresponds to Tibetan dgu. In Mara, the *t- prefix went through affrication and became $c h-[t s-]$, resulting in *ta-ki > tsa-ki.

\subsection{The reconstruction of numeral ten}

Van Bik (2009) reconstructs two proto words for numeral ten, *soom and *hraa. We see in Table 10 that the Sizang and Thado-Kuki cognates of numeral ten differ from rest of the languages in the root final. Languages with the $h r$ - initial do not have a nasal final, while Thado-Kuki and Sizang have a nasal final. Another element for 'ten', as used in numerals from thirty in Hyow, as in thúnggíp (three-ten) 'thirty' is cognate with Karbi kēp (Konnerth, 2014: 192) and found outside тв, as in Old Chinese dzyip < *t.[g] əp (Baxter and Sagart, 2014: 359). Therefore, the KC numeral ten is innovative. In Zophei, the word for numeral ten is ron. I have already mentioned that for the *hr- $>$ *hy- $>s-/ \int-|\chi-| x$-is pos- 
TABLE 11 Differences of root-initials of numerals between VanBik and proposed reconstructions

PKC (VanBik, 2009) Proposed revision Gloss

\begin{tabular}{lll}
\hline *khat/Rat/hat & *k-hngat, *t-ak & 'one' \\
*ni?/*hni? & *k-ni? & 'two' \\
*thum & *k-thum & 'three' \\
*lii & *p-lii & 'four' \\
*ngaa & *p-nga & 'five' \\
*ruk & *t-ruk & 'six' \\
*ri? & *s-k-ri? & 'seven' \\
*riat & *p-riat & 'eight' \\
*kua & *t-kua & 'nine' \\
*soom, hraa & *soom, *hraa, *gip 'ten' \\
\hline
\end{tabular}

sible (see Section3.6). Hence, it is possible that Mizo sàwm, Sizang sôm and Thado Kuki sòom originated in VanBik's PKC *hraa 'ten'. The problem is Mizo s-, Sizang $s$ - and Thado Kuki $s$ - do not regularly correspond with PKC *hr-. Therefore, Van Bik is right in reconstructing both *soom and *hraa for numeral ten. The voiceless velar initial in the Asho cognate pan.ya for numeral ten demonstrates an assimilation of the root-initial $y$ - with the - $n$ final of the classifier $p ə n$. There are no prefixes to be reconstructed for numeral ten.

The proposed reconstructions of numerals which I have made so far significantly differ from that of with Van Bik's (2009) mostly because I have reconstructed the numerals along with the prefixes attached to the root. Reconstructing the prefixes has particularly helped to explain the voiceless root initials of numeral four and five in the sc languages. Note that reconstructing the voiceless prefixes for numerals has consistently accounted for the voiceless root-initials of numeral two, four, five, six and seven in sc languages while the devoicing effect is particularly absent in Central and Northeastern languages, except for the numeral four in Hakha and in languages which have a regularized prefix $p$-, as in Taungtha or $l o$-, as in Mro-Khimi varieties. I summarize the revised reconstructions above for the convenience of the discussion in Table 11.

It is important to note that Sizang shows $l$ - as root initial for numeral 'six', 'seven' and 'eight'. ${ }^{19}$ Not only for these three numerals, but also for the word

19 Usually, $\mathrm{PKC}{ }^{*} \mathrm{r}$ - is reflected as Sizang $n g$-. 
TABLE 12 Revision of VanBik's * $y-$

\section{KVB (2009) Revised reconstructions Gloss}

\begin{tabular}{lll}
\hline *yu & *pa-hyu & 'mouse' \\
*yung & *hyung & 'be dark' \\
*yang & *hyang & 'light (weight)' \\
*yul & *hyul & 'follow' \\
*yun & *p-hyun & 'urine' \\
\hline
\end{tabular}

'pheasant' Sizang va-lik< PKC * rik or *hrik (Van Bik, 2009: 240), Sizang reflects l- root-initial. Note that PKC *ray-I, *ran-II > Mara pa-rá and Sizang man lāng 'fast/quick' (VanBik, 2009: 236). I propose that in Sizang $l-<{ }^{*} \mathrm{r}$ - happens after a prefix or a morpheme. The proposal is strongly supported by the fact that PKC * $r$ - does not have regular reflexes of $\gamma$ - and $j$-respectively in presence of inherited prefixes in Changpyang and Wakung (see Section 4.8).

\section{$5 \quad$ Summary}

In addition to reconstructing the numerals, I have so far revised Van Bik's reconstructions of words with PKC * $y$ - and *r-initials. I have shown that Van Bik's reconstruction of ${ }^{*} \mathrm{~s}^{\mathrm{h}}$ - as separate from ${ }^{*} \mathrm{~s}$ - is insufficiently warranted (see Section 3.2).

Van Bik (2009) does not reconstruct the *hy- initial in PKC. However, I have provided evidence showing some of the words Van Bik reconstructed with the *y- initial should be reconstructed with the *hy- root initial, as repeated in Table 12.

The list of reconstructed words in Table 12 is not exhaustive. Any future work on the reconstruction of PKC should carefully look into the words that Van Bik (2009) reconstructed with *y-.

Some words that Van Bik (2009) reconstruct with ${ }^{*} \mathrm{r}$ - and ${ }^{*} \mathrm{hr}$ - required revision in light of the new data on sc languages. The proposed reconstructions are presented in Table 13 .

Perhaps, the words reconstructed with * $r$ - and *hr- require the most careful and exhaustive work in the future due to the unpredictable reflexes in Sizang and Sc languages. There seems to be an explanation for the unexpected outcome of * $r$ - as $l$ - in Sizang numerals, namely that this change was conditioned by the presence of a prefix. However, this matter requires further study. 


\begin{tabular}{lll}
\hline KVB (2009) & Revised reconstructions & Gloss \\
\hline${ }^{*}$ ruul & ${ }^{*}$ s-p-ruul & 'snake' \\
${ }^{*}$ ru? & ${ }^{*}$ s-ru? & 'bone' \\
${ }^{*}$ rum & ${ }^{*}$ s-rum & 'pointed (sharp)' \\
${ }^{*}$ ril & ${ }^{*}$ hril & 'intestine' \\
NA & ${ }^{*}$ s-ruk & 'whistle' \\
NA & ${ }^{*}$ hril & 'breather' \\
NA & ${ }^{*}$ hren & 'silver' \\
NA & *hrim & 'old/ancient'
\end{tabular}

The data presented in this paper and the LSDO wordlist provide evidence for PKC * $r$ - being retained in all the cognates in Thaiphum, which is classified as a Southern Khumi in the LSDO dataset. Peterson (2017) notes that Khumi shows various treatments of PKC *r-. Thaiphum also shows preserving old prefixes. The documentation of Thaiphum and Mrusa promises to provide useful data for comparative analysis and historical phonology of Kc languages.

The irregular correspondences in the cognates of SC languages are largely due to prefixation. The extensive use of assimilation in sc languages make the reconstruction work very difficult. The reconstruction of PKC requires a revision with updated data and inclusion of equal representatives of the daughter languages from each of the subgroups-Northwestern, Central, and Peripheral. Even my proposed reconstructions require further polishing using data from Northwestern languages. However, provided the conservative nature of Central and some sc languages, e.g. Hyow, the proposed reconstructions will benefit any future endeavor. The reconstruction proposed by Van Bik, Khoi and others show that the languages of the Northwestern and Central subgroups are relatively stable in mirroring the reflexes of the protoforms, while the languages of the Peripheral subgroups show greater variation. Any future study in PKC phonology should take a closer look into the prefixes and reflexes of the PKC finals. 


\section{References}

Baxter, William and Sagart, Laurent. 2014. Old Chinese: A new reconstruction. Oxford: Oxford University Press.

Benedict, Paul K. 1940. Studies in Indo-Chinese Phonology. Harvard Journal of Asiatic Studies, 5.2: 101-127.

Benedict, Paul K. 1972. Sino-Tibetan: A Conspectus. Cambridge: University Press.

Bhaskararao, Peri. 1996. A Computerized Lexical Database of Tiddim Chin and Lushai. Tokyo: ILCAA, Tokyo University of Foreign Studies.

Bradley, David. 1997. Tibeto-Burman languages and classification. In Papers in Southeast Asian Linguistics, Bradley, David. (ed.), 14: Tibeto-Burman Languages of the Himalayas, 1-72. Canberra: Australian National University.

Bradley, David. 2005. Why do numerals show 'irregular' correspondence patterns in Tibeto Burman? Some Southeastern Tibeto-Burman examples. Cahiers de linguistique-Asie orientale, 34.2: 221-238.

Button, Christopher. 2011. Proto Northern Chin. STEDT Monograph Series 1o. Berkeley, CA: University of California Press.

Changte, Lalnunthangi. 1993. Mizo Syntax. Oregon: University of Oregon Ph.D. thesis.

Dempsey, Jacob M. 1995. A reconsideration of some phonological issues involved in reconstructing Sino-Tibetan numerals. Seattle: University of Washington dissertation.

Fellner, Hannes and Hill, Nathan W. 2019. Word families, allofams, and the comparative method. Cahiers de Linguistique Asie Orientale, 48 (2): 91-124.

Fryer, G. 1875. On the Khyeng People of the Sandoway District, Arakan. Journal of the Asiatic Society of Bengal, XLIV(1): 39-82.

Hale, Mark. 2007. Historical linguistics: Theory and method. Oxford: Blackwell.

Hale, Mark. 2014. The Comparative Method: theoretical issues. In Claire Bowern and Bethwyn Evans (eds.), The Routledge Handbook of Historical Linguistics, 146-16o. Abingdon-on Thames: Routledge.

Handel, Zev. 2019. A brief response to Fellner and Hill's "Word families, allofams, and the comparative method". Cahiers de Linguistique Asie Orientale, 48.2: 125-141.

Hartmann-So, Helga. 2009. A descriptive grammar of Daai Chin. Berkeley: Sino Tibetan Etymological Dictionary and Thesaurus Project, Dept. of Linguistics research unit in University of California.

Hetzron, Robert. 1976. Two principles of genetic reconstruction. Lingua, 38(2): 89108.

Hill, Nathan. (2014). Proto-Kuki-Chin initials according to Toru Ohno and Kenneth Van Bik. Journal of the Southeast Asian Linguistics Society (JSEALS), 7: 11 30. Canberra: Asia-Pacific Linguistics.

Hill, Nathan. 2019. The Historical Phonology of Tibetan, Burmese, and Chinese. Cambridge: Cambridge University Press. 
Hodson, Thomas. 1905. Thado Grammar. Shillong: The Eastern Bengal and Assam Secretariat Printing Office.

Hoijer, Harry. 1966. Hare phonology: an historical study. Language, 32: 499-507.

Hornéy, Christina S. 2012. A phonological analysis of Mro Khimi. North Dakota: University of North Dakota MA thesis.

Houghton, Bernard. 1892. Essay on the language of the Southern Chins and its affinities. Rangoon: Supt., Govt. Print., Burma.

Hyman, Larry M. and Kenneth, Van Bik. 2002. Tone and stem2-formation in Hakha Lai. Linguistics of the Tibeto-Burman Area, 25:113-121.

Jacques, Guillaume. 2011. A panchronic study of aspirated fricatives, with new evidence from Pumi. Lingua, 121.9: 1518-1538.

Jacques, Guillaume. 2004. Phonologie et morphologie du japhug (Rgyalrong). Thèse de doctorat, Université Paris VII-Denis Diderot.

Jacques, Guillaume. 2017. The morphology of numerals and classifiers in Japhug. In Sociohistorical Linguistics in Southeast Asia, Picus Sizhi Ding \& Jamin Pelkey (eds.), 135-148. Leiden: Brill.

Joorman, H. 1906. Chin grammar. Rangoon: American Baptist Mission Press.

Jordan, Marc. 1969. Chin Dictionary and Grammar. Paris: L'Ambassade de L' Union de Bermanie.

King, Deborah. 2009. Structural And Pragmatic Functions Of Kuki-Chin Verbal Stem Alternations. Journal of the Southeast Asian Linguistics Society, 1:141-157.

Konow, Sten. 1904. Specimens of the Kuki-Chin and Burma Groups. In Linguistic Survey of India, Grierson, George (ed.), Vol. III, Tibeto-Burman Family Part 3. Calcutta, India: Office of the Superintendent of Government Printing.

Konnerth, Linda. 2014. A grammar of Karbi. Oregon: University of Oregon Doctoral dissertation.

Language and Social Development Organization. 2019. A Chin dialect survey (Part 1 of 2) [Data set]. Zenodo. http://doi.org/10.5281/zenodo.3344667

Language and Social Development Organization. 2019. A Chin dialect survey (Part 2 of 2) [Data set]. Zenodo. http://doi.org/10.5281/zenodo.3345०35

Löffler, Lorenz G. 2002. Some Notes on Maraa. Linguistics of the Tibeto-Burman Area, 25.1: $123-136$.

Lotven, Samson, Berkson, Kelly, Wamsley, James C., et al. 2020. The syllable in Kuki Chin. Journal of South Asian Languages and Linguistics, 6.1: 1-17.

Luce, George. 1985. Phases of Pre-Pagan Burma (2 volumes). Oxford: Oxford University Press.

Matisoff, James A. 2003. Handbook of Proto-Tibeto-Burman: System and Philosophy of Sino-Tibetan Reconstruction. Berkeley, CA: University of California Press.

Mortensen, David. 2003. Comparative Tangkhul. Ms.

Ohno Toru 大野徹. 1965. “共通クキ・チン語の構成(1)-語頭子音 Kyotsu-kuchi chin 
go no saikosei I: Goto shi in [The Reconstruction of Proto-Kuki-Chin 1: initials]" 言 語 究 Gengo Kenkyū (Journal of the Linguistic Society of Japan), 47·3: 8-20.

Peterson, David. 2000. On the Status of the sc Subgroup. The 33rd International Conference on Sino Tibetan Languages and Linguistics. Bangkok: Ramkhamhaeng University.

Peterson, David. 2003. Agreement and grammatical relations in Hyow. In Language variation: papers on variation and change in the Sinosphere and in the Indosphere in honour of James A. Matisoff, David Bradley, et al. (eds.), 173-183. Canberra: Pacific Linguistics.

Peterson, David. 2014. Kuki-Chin Directional Systems Revisited. The $47^{\text {th }}$ International Conference on Sino-Tibetan Languages and Linguistics. Yunnan.

Peterson, David. 2017. On Kuki-Chin subgrouping. In Sociohistorical Linguistics in Southeast Asia: New Horizons for Tibeto-Burman Studies in Honor of David Bradley, Picus Sizhi Ding \& Jamin Pelkey (eds.), 189-209. Leiden: Brill.

Rundall, Frank. 1891. Manual of the Siyin Dialect. Rangoon: The Superintendent, Government Printing, Burma.

Shafer, Robert 1940. The Vocalism of Sino-Tibetan. Journal of the American Oriental Society, 6o.3: 302-337.

Shafer, Robert. (1955), Classification of the Sino-Tibetan languages. Word, 11.1: 94-111. London: Taylor \& Francis.

Solnit, David B. 1979. Proto-Tibeto-Burman *r in Tiddim Chin and Lushai. Linguistics of the Tibeto Burman Area, 4: 2: 111-121.

Thang, Khoi Lam. 2001. A Phonological Reconstruction of Proto Chin. Chiang Mai, Thailand: Payap University MA thesis.

Tignor, Daniel. 2018. A Phonology Of Hill (kone-Tu) Asho. North Dakota: University of North Dakota MA thesis.

Van Bik, Kenneth. 2009. Proto-Kuki-Chin: a reconstructed ancestor of the Kuki Chin languages. Berkeley: Sino-Tibetan Etymological Dictionary and Thesaurus Project, Dept. of Linguistics research unit in University of California.

Weera, O. (1998). Tiddim Chin tones in historical perspective. Linguistics of the TibetoBurman Area, 21.1: 235-248.

Zakaria, Muhammad. 2017. A Grammar of Hyow. Singapore: Nanyang Technological University Doctoral dissertation.

Zhang, Shuya. 2020. Le rgyalrong situ de Brag-bar et sa contribution à la typologie de l'expression des relations spatiales: l'orientation et le mouvement associé. Linguistique. Institut National des Langues et Civilisations Orientales. 